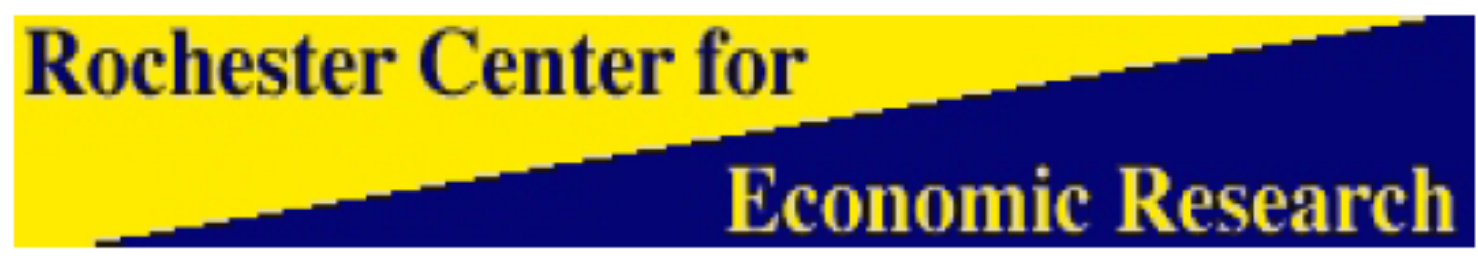

Optimal Taxation with Private Insurance

Yongsung Chang and Yena Park

Working Paper No. 599

March 2017 


\title{
Optimal Taxation with Private Insurance *
}

\author{
Yongsung Chang \\ Yena Park \\ University of Rochester \\ University of Rochester \\ Yonsei University
}

February 28, 2017

\begin{abstract}
We derive a fully nonlinear optimal income tax schedule in the presence of a private insurance market. The optimal tax formula is expressed in terms of sufficient statistics - such as the Frisch elasticity of labor supply, social preferences, and hazard rates of the income distributions - as in the standard Mirrleesian taxation without private insurance (e.g., Saez (2001)). However, in the presence of a private market, the standard sufficient statistics are no longer sufficient. The optimal tax rate also depends on how private savings interact with public insurancethrough substitution and crowding in/out. Based on our formula, we compute the optimal tax schedule using a quantitative general equilibrium model calibrated to reproduce the U.S. income distribution.
\end{abstract}

Keywords: Optimal Taxation, Private Insurance, Crowding Out, Mirrelsian Tax JEL Classification: H21, H23, D51

${ }^{*}$ We would like to thank Anmol Bhandari, Narayana Kocherlakota, Kjetil Storesletten, and Maxim Troshkin for helpful comments. 


\section{Introduction}

What is the socially optimal shape of the income tax schedule? This has been one of the classic and central questions in macroeconomics and pubic finance. Despite significant progress in the literature, surprisingly few studies have investigated the role of private intermediation in the optimal tax system. Given that almost all households have access to financial markets, it is important to understand the interaction between private and public insurance to determine the optimal tax-andtransfer system. In this paper, we study the optimal (fully) nonlinear income tax schedule in the presence of private intermediation.

In the classic Mirrleesian approach (Mirrlees (1971)), which studies how to design social insurance in the presence of information frictions, it is commonly assumed that the government is the only provider of insurance. While Chetty and Saez (2010) are the exception in the static Mirrleesian literature, they assume a linear functional form for both the tax schedule and private insurance. In the dynamic Mirrleesian literature (the so-called new dynamic public finance), Golosov and Tsyvinski (2007) allow private insurance but with a specific market structure - a competitive insurance industry with private information friction. Given that the government and private firms face the same information friction, the role of the government is restricted to internalize the pecuniary externalities, and thus, there are limited implications for the optimal shape of the tax schedule.

In the alternative Ramsey approach (Ramsey (1927)), which examines the optimal tax schedule within a class of functional forms, many studies have provided quantitative answers as to the optimal amount of redistribution in the presence of self-insurance opportunities (e.g., Aiyagari and McGrattan (1998), Conesa and Krueger (2006), Conesa, Kitao, and Krueger (2009), Heathcote, Storesletten, and Violante (2014), and Bhandari, Evans, Golosov, and Sargent (2016)). However, these studies assume a parametric form for the tax schedule - either affine or log-linear. Moreover, they do not particularly focus on the role of private insurance-how the introduction of private savings affects the optimal tax schedule.

In this paper, we study a fully nonlinear optimal income tax schedule in the presence of private market intermediation. Different from the Mirrleesian approach, which solves a mechanism design problem with information friction, we use a variational approach as in Saez (2001) and Golosov, Tsyvinski, and Werquin (2014). Different from the Ramsey approach, we do not impose a parametric functional form on the tax system. We study a fully nonlinear optimal income tax schedule within a class - i.e., an age-independent and time-invariant tax that is levied on current income 
only. This allows a direct comparison of our results to those in the static Mirrleesian and Ramsey literatures.

We derive the optimal tax formula under a very general representation of private market intermediation. As in Saez (2001), the optimal tax formula is expressed in terms of standard sufficient statistics - such as the Frisch elasticity of labor supply, the hazard rate of the income distribution, and marginal social welfare weights. In the presence of a private market, however, these sufficient statistics are no longer sufficient. The optimal tax formula also includes additional statistics that capture the interaction between private and public insurance - such as the substitution between the two types of insurance and crowding in/out of private intermediation by the government tax/transfer.

Our formula provides transparent and intuitive insights about the role of the private insurance market in the optimal tax schedule. First, it captures the fact that public and private insurance are substitutes - a higher marginal private intermediation (e.g., high savings rate) leads to a lower marginal tax rate at a given level of income. Second, the original formula in Saez (2001) is modified to reflect the amplifying (or mitigating) factors that stem from private intermediation. Two components are important for this amplification (or mitigation): (i) the marginal propensity to consume (1- marginal private intermediation) and (ii) cross-sectional consumption inequality, which depends on the distribution of wealth. The Saez formula is amplified if the marginal propensity to consume is larger than one (e..g, a negative marginal savings rate) and/or if the consumption inequality is larger (e..g, a large wealth inequality) in the presence of private intermediation. Third, it depends on the cross-sectional distribution of crowding in/out effects. More specifically, a tax reform is more effective when the response of private intermediation is aligned with the reform. For example, increasing the marginal tax rate is more desirable when private insurance also becomes more progressive - e.g., the rich save more in response to such tax reform.

Our optimal tax formula requires the cross-sectional pattern of crowding-in/out elasticity, which is very difficult to estimate from the data. We obtain these elasticities from a quantitative general equilibrium incomplete-markets model (Huggett (1993)), which is calibrated to resemble some salient features of the U.S. economy (such as the income distribution). This allows us to quantify the role of private insurance in the optimal tax schedule.

Our results show that the presence of a private intermediation is quantitatively important, as the difference in optimal tax rates (with and without private insurance) can be as large as 10 percentage 
points. Moreover, the difference in tax rates with and without a private intermediation is not in the same direction in all income groups. For the low and lower-middle income groups where the marginal intermediation is negative, the optimal tax rates are higher than those without private markets, mainly because of the amplified Saez effects. For the upper-middle to high income groups where the marginal intermediation is positive, the substitution effect and the mitigating effect in the Saez formula dominate, resulting in lower tax rates in the presence of a private market. At the very top income group, these forces almost cancel out each other, leaving the tax rate similar to that without private insurance. We also show that the impact of private insurance - via substitution, amplification/mitigation of Saez, and crowding in/out effects - depends on fundamental parameters such as risk aversion, the Frisch elasticity of labor supply, borrowing constraint, and the shape of the productivity distribution.

The remainder of the paper is organized as follows. Section 2 provides a brief literature review. In section 3, we derive the optimal tax formula using a variation approach. Section 4 presents our benchmark quantitative analysis and Section 5 provides various comparative statistics with respect to the fundamental parameter values. Section 6 concludes.

\section{Relation to the Literature}

Our paper is related to a large literature on the optimal income tax/transfer system. In the Mirrleesian literature, which solves the planner's problem under private information, the optimal shape of the nonlinear income tax has been studied in a static environment (Saez (2001) and Diamond (1998)). While the optimal labor wedge has been studied in a stochastic dynamic environment (Farhi and Werning (2013), Golosov, Troshkin, and Tsyvinski (2016) among others), the Mirrleesian literature largely abstracts from private insurance market by assuming that the government is the sole provider of insurance.

Chetty and Saez (2010) and Golosov and Tsyvinski (2007) are the exceptions that allow for a private insurance market in the Mirrleesian literature. However, their questions are centered on the welfare gains from government intervention in the presence of private insurance. Chetty and Saez (2010) also point out that the optimal tax formula should take into account the interplay between the government and the private market, especially when the private market suffers from moral hazard or adverse selection. But they assume that both private and public insurance are linear, and thus have limited implications for the optimal tax schedule. Golosov and Tsyvinski 
(2007) examine a dynamic environment in the presence of a competitive insurance market where private information is the only friction and find an important role for government intervention if households secretly trade risk-free bonds. We derive the optimal nonlinear tax formula under a very general representation of private intermediation. Thus, our formula can be applied to various market structures, regardless of the source of frictions in private intermediation.

In the Ramsey taxation literature, which focuses on a class of parametric functional forms for tax, the previous studies with private insurance (such as Conesa and Krueger (2006), Conesa, Kitao, and Krueger (2009), Heathcote, Storesletten, and Violante (2014), and Heathcote and Tsujiyama (2017), among others) are complementary to our paper. While we allow for a fully nonlinear tax system, our analysis provides a transparent comparison to these papers, as we also compute the optimal tax schedule in a general equilibrium incomplete-markets economy - a workhorse model in macroeconomics. Our quantitative analysis shows that the optimal tax schedule is very different from those commonly assumed - an affine or log-linear tax function — in the literature. ${ }^{1}$

Our paper is also related to the "variational approach" literature, which builds on the perturbation method developed by Saez (2001) in a static economy and allows us to express the tax formula in terms of the the so-called sufficient statistics. Recently Golosov, Tsyvinski, and Werquin (2014) and Saez and Stantcheva (2016) have also extended this method to a dynamic environment.

Outside the optimal taxation literature, several papers study the interaction between private and public insurance. Attanasio and Ríos-Rull (2000) examine the relationship between compulsory public insurance (against aggregate shocks) and private insurance against idiosyncratic shocks. Krueger and Perri (2011) study the crowding-out effect of progressive income tax on private risksharing motive under limited commitment.

\section{Optimal Nonlinear Tax Formula with Private Insurance}

\subsection{Restrictions on the Tax System}

While we consider a fully nonlinear income tax system without assuming a functional form, we focus on a restrictive class of tax system. The class of tax system we consider is a nonlinear labor-

\footnotetext{
${ }^{1}$ For example, Heathcote and Tsujiyama (2017) compare three tax systems (affine, log-linear, and Mirrleesian) and find that the optimal tax schedule is close to a log-linear form. Our analysis shows that under a more realistic productivity distribution and private market structure, the optimal tax schedule is highly nonlinear-quite different from log-linear.
} 
income tax with a lump-sum transfer. ${ }^{2}$ More precisely, (i) a (fully) nonlinear labor-income tax $T(z)$ where $z$ is current labor income; (ii) the tax is levied on current period's income only (no history dependency); and (iii) the nonlinear tax function $T(z)$ is age-independent and time invariant.

We impose these restrictions because they allow for a direct comparison to the static Mirrleesian taxation and Ramsey taxation literature. On one hand, in a static Mirrleesian analysis, the laborincome tax depends on income only (not on productivity) because of information frictions. However, in a dynamic environment with stochastic productivity - which we study here - the optimal allocation that solves a mechanism design problem with information frictions (as in the new dynamic public finance) will depend on the history of incomes. Moreover, it is well known that a tax system that can implement the constrained-efficient allocation is highly complicated, and thus a direct comparison of tax schedules between a static and a dynamic environment is not straightforward, even without a private market. ${ }^{3}$ On the other hand, the Ramsey literature focuses on a tax system with particular functional forms. As in the Ramsey literature, our analysis starts with a simple and implementable tax system, but allows for a fully nonlinear functional form. Thus, our analysis provides a transparent comparison to the theoretical results from Mirrleesian taxation as well as those from Ramsey taxation.

\subsection{Economic Environment with Private and Public Insurance}

Consider an economy with a continuum of workers with measure one. Workers face uncertainty about their labor productivity in the future. The individual productivity shock $x_{t}$ follows a Markov process (which will be specified below) that has an invariant stationary (cumulative) distribution $F(x)$ whose probability density is $f(x)$.

Individual workers have an identical utility function $\sum_{t=0}^{\infty} \beta^{t} E_{0}\left[U\left(c_{t}, l_{t}\right)\right]$, where an instantaneous utility $U(c, l)$ has the following form:

$$
U(c, l)=u(c-v(l))
$$

where $u($.$) is concave and increasing in consumption c$ and $v($.$) is convex and increasing in labor$ supply $l$. We focus on households' preferences that have no wealth effect on the labor supply (the

\footnotetext{
${ }^{2}$ We can allow for capital income tax, but we focus only on the optimal labor-income tax for a given capital income tax, without considering joint optimal taxation.

${ }^{3}$ Most studies in the new dynamic public finance literature compare the implicit wedge from a dynamic environment to the marginal tax rate from a static one.
} 
so-called GHH preferences by Greenwood, Hercowitz, and Huffman (1988)). This assumption is common in the literature because it significantly simplifies the optimal tax formula. The earnings of a worker whose current productivity is $x_{t}$ are $z_{t}=x_{t} l_{t}$. The cumulative distribution of earnings is denoted by $H(z)$ whose density function is $h(z)$.

The government provides insurance through a (time-invariant) nonlinear labor-income tax and lump-sum transfer system where the net payment schedule is denoted by $T\left(z_{t}\right)$. The after-tax labor income is $y_{t}=z_{t}-T\left(z_{t}\right)$. Workers can also participate in a private market to insure against their income uncertainty. Denote the individual state in period $t$ by $\left(z_{t}, \mathbf{s}_{t}\right)^{4}$, where $\mathbf{s}_{t}=\left(s_{1, t}, \cdots, s_{M, t}\right) \in$ $R^{M}$ is the vector of individual state variables other than labor income. For example, if the private insurance market is a Bewley-type incomplete market and consumers can only self-insure themselves by saving and borrowing via a non-contingent bond (e.g., Huggett (1993)), we need only one additional state variable: bond holdings $a_{t}: \mathbf{s}_{t}=a_{t}$.

We denote the net payment from private insurance (payment - receipts) by $P_{t}\left(z_{t}, \mathbf{s}_{t} ; T\right)$. Thus, consumption is $c_{t}\left(z_{t}, \mathbf{s}_{t}\right)=z_{t}-T\left(z_{t}\right)-P_{t}\left(z_{t}, \mathbf{s}_{t} ; T\right)$. This representation is very general. The only assumption we make is that the sum of the net payment in the private intermediation is zero: $\int P(\cdot)=0 .{ }^{5}$ In a Huggett economy with self-insurance only, $P_{t}\left(z_{t}, a_{t}\right)=a_{t+1}\left(z_{t}, a_{t}\right)-(1+r) a_{t}$ where $r$ is the rate of return on bond holdings.

The government chooses a tax/transfer schedule $T(z)$ to maximize the following social welfare function (SWF):

$$
S W F=E\left[\sum_{t=0}^{\infty} \beta^{t} G\left(U\left(c_{t}, l_{t}\right)\right)\right],
$$

where $G(\cdot)$ is an increasing function that reflects the social preferences for redistribution.

Since the private intermediation $P(\cdot ; T)$ depends on the government tax/transfer schedule $T$, the government chooses the optimal $T$ taking into account this interaction between public and private insurance. From now on, to simplify the notation, we will suppress $T$ in $P(\cdot)$ unless necessary. We will also express the private intermediation as a function of after-tax income $y$ : $\tilde{P}(y, \mathbf{s} ; T)=\tilde{P}(z-T(z), \mathbf{s} ; T)=P(z, \mathbf{s} ; T)$.

\footnotetext{
${ }^{4}$ Alternatively, the state can be expressed as $\left(x_{t}, \mathbf{s}_{t}\right)$. With no income effects on labor supply, labor income $z_{t}$ and productivity $x_{t}$ have a one-to-one relationship and we can use them interchangeably.

${ }^{5}$ That is, we consider a pure insurance market where the aggregate transfer is exactly funded by the aggregate payment in each period.
} 


\subsection{Deriving Taxation Formula with Private Insurance}

In deriving the optimal tax formula, we apply the variational approach (Saez (2001); Golosov, Tsyvinski, and Werquin (2014)). Instead of solving a mechanism design problem, we find a fully nonlinear marginal tax schedule that maximizes social welfare. That is, we consider a perturbation (a small deviation) from a given nonlinear tax schedule. If there is no welfare-improving perturbation within the class of tax system, the given tax schedule is optimal.

For a given income tax schedule $T(z)$, the economy we consider converges to a steady state where the distribution of state variables $\Phi(z, \mathbf{s})$ is stationary. We assume that in period 0 the economy starts from that steady state. Consider a (revenue-neutral) tax reform that increases the marginal tax rate $T^{\prime}(z)$ by $\delta \tau$ on the income bracket $\left[z^{*}, z^{*}+d z^{*}\right]$, as in Saez (2001).

In order to analyze the welfare effects of a tax reform (in the presence of a private insurance market), it is important to study its impact on the household's total intermediation for insurance: government tax/transfer plus private intermediation. Denote the total intermediation by $M_{t}(z, \mathbf{s})=$ $T(z)+P_{t}(z, \mathbf{s} ; T)$. Since the government takes into account the response of households, the optimal tax depends on the following factors at a given income level: (i) the level of marginal private intermediation (e.g., marginal savings rate) — which we call the "substitution" effect, (ii) the response (change) of the private intermediation schedule — which we call the "crowding in/out" effect, and (iii) the response of the labor supply — which we call the "behavioral" effect. We now study each of these effects below.

\subsubsection{Effects on Total Intermediation}

The total marginal intermediation at income level $z$ is:

$$
M_{t}^{\prime}(z, \mathbf{s})=T^{\prime}(z)+P_{t}^{\prime}(z, \mathbf{s}) .
$$

Within the income band $\left[z^{*}, z^{*}+d z^{*}\right]$, where the marginal tax rate is changed, the change in the marginal total intermediation $d M^{\prime}$ reflects the change in the marginal tax itself, $d T^{\prime}\left(z^{*}\right)$, and that in the marginal private intermediation, $d P^{\prime}\left(z^{*}, \mathbf{s}\right)$. The marginal private intermediation can change via two channels: (i) a change in after-tax income $(-\delta \tau)$ and (ii) a change in the marginal private payment schedule (change in $\left.\tilde{P}^{\prime}\right) .{ }^{6}$ The sum of these two changes is:

$$
d^{o} P_{t}^{\prime}\left(z^{*}, \mathbf{s}\right)=-\tilde{P}^{\prime}\left(y^{*}, \mathbf{s}\right) \delta \tau+\left.d^{o} \tilde{P}_{t}^{\prime}\right|_{y^{*}} \cdot\left(1-T^{\prime}\left(z^{*}\right)\right),
$$

\footnotetext{
${ }^{6} P^{\prime}\left(z^{*}, \mathbf{s}\right)=\frac{d P}{d y} \frac{d y}{d z}=\tilde{P}^{\prime} \cdot\left(1-T^{\prime}\left(z^{*}\right)\right)$ where $\tilde{P}(y, \mathbf{s})=\tilde{P}(z-T(z), \mathbf{s})=P(z, \mathbf{s} ; T)$.
} 
where $d^{o} X$ denotes the change in $X$ due to a tax increase in its own income bracket-as opposed to the change in $X$ due to a tax increase in other income brackets.

Note that $\left.d^{o} \tilde{P}^{\prime}\right|_{y^{*}}$ denotes the change in the marginal private payment schedule $\left(\tilde{P}^{\prime}(y, \mathbf{s})\right)$ for a given after-tax income $y^{*}=z^{*}-T\left(z^{*}\right)$. Thus, the change in the total marginal intermediation is:

$$
d^{o} M_{t}^{\prime}\left(z^{*}, \mathbf{s}\right)=\left(1-\tilde{P}^{\prime}\left(y^{*}, \mathbf{s}\right)\right) \delta \tau+\left.d^{o} \tilde{P}_{t}^{\prime}\right|_{y^{*}} \cdot\left(1-T^{\prime}\left(z^{*}\right)\right)
$$

It is easier to understand these terms in the context of a Huggett (1993) economy with self-insurance. The first term reflects an increase in the total marginal tax at a given marginal propensity to save $\tilde{P}_{y}^{\prime}$. The second term represents the change in the marginal private savings rate at a given disposable income level - which we refer to as the own-crowding in/out effect. We call this the own crowding effect because it reflects the change in marginal private savings at the income level where the tax rate is changed. As we will discuss below, the private savings rate may also change when the marginal tax rate in other income levels changes - via changes in permanent income. We refer to such changes in private intermediation as the cross-crowding in/out effects.

Using a similar definition for the elasticity of the own-crowding out $r_{t}^{o}(z, \mathbf{s})$, as in Chetty and Saez $(2010),{ }^{7}$ the change in total intermediation $d^{o} M_{t}^{\prime}\left(z^{*}, \mathbf{s}\right)$ can be expressed as:

$$
\begin{aligned}
d^{o} M_{t}^{\prime}\left(z^{*}, \mathbf{s}\right) & =\left(1-r_{t}^{o}\left(z^{*}, \mathbf{s}\right)\right)\left(1-\tilde{P}_{t}^{\prime}\left(y^{*}, \mathbf{s}\right)\right) \delta \tau, \quad \text { where } \\
r_{t}^{o}(z, \mathbf{s}) & =-\frac{\left.d^{o} \log \left(1-\tilde{P}_{t}^{\prime}\left(y^{z}, \mathbf{s}\right)\right)\right|_{y^{z}}}{d \log \left(1-T^{\prime}(z)\right)}
\end{aligned}
$$

To better understand $d^{o} M_{t}^{\prime}\left(z^{*}, \mathbf{s}\right)$, note that the marginal propensity to consume out of before-tax income $z$ is $\frac{d c}{d z}=1-M_{t}^{\prime}(z, \mathbf{s})$. Thus, an increase in the total marginal intermediation is equivalent to a decrease in marginal consumption. If there is no crowding out of private intermediation $\left(r^{o}=0\right)$, the decrease in marginal consumption is simply the marginal propensity to consume multiplied by the changes in the tax rate $\left(1-\tilde{P}^{\prime}\right) \delta \tau$. However, because of the crowding in/out effect of a tax increase on private intermediation, the increase in the total marginal intermediation is smaller than $\left(1-\tilde{P}^{\prime}\right) \delta \tau$.

In a dynamic environment where individual productivity stochastically changes over time, there can be additional effects on private intermediation because permanent (or future) income changes. For example, in an economy with self-insurance, while tax reform is confined to the income region of $\left[z^{*}, z^{*}+d z^{*}\right]$ only, private savings in other income regions also change. We refer to this effect as the

\footnotetext{
${ }^{7}$ Chetty and Saez (2010) define the degree of crowding out in terms of linear (public and private) savings.
} 
cross crowding in/out effect. For each income level $z$, the change in total marginal intermediation via the cross crowding out effect can be expressed as:

$$
\begin{aligned}
d^{c} M_{t}^{\prime}(z, \mathbf{s}) & =\frac{\left.d^{c} \tilde{P}_{t}^{\prime}\left(y^{z}, \mathbf{s}\right)\right|_{y^{z}}}{d T^{\prime}\left(z^{*}\right)}\left(1-T^{\prime}(z)\right) \delta \tau d z^{*} \\
& =-r_{t}^{c}(z, \mathbf{s}) \frac{\left(1-P_{t}^{\prime}(z-T(z), \mathbf{s})\right)\left(1-T^{\prime}(z)\right)}{1-T^{\prime}\left(z^{*}\right)} \delta \tau d z^{*}
\end{aligned}
$$

where $d^{c} P_{t}^{\prime}\left(y^{z}, \mathbf{s}\right)$ denotes the changes in the marginal private intermediation schedule due to cross crowding out at a given after-tax income $y^{z}$ and $r_{t}^{c}(z, \mathbf{s})$ is the elasticity of cross crowding out in the marginal private intermediation:

$$
r_{t}^{c}(z, \mathbf{s})=-\frac{\left.d^{c} \log \left(1-\tilde{P}_{t}^{\prime}\left(y^{z}, \mathbf{s}\right)\right)\right|_{y^{z}}}{d \log \left(1-T^{\prime}\left(z^{*}\right)\right)} .
$$

To summarize, in an income band where the marginal tax rate has increased, the total marginal intermediation changes due to (i) the increase in the marginal tax rate itself and (ii) the own crowding in/out of private intermediation. For all income levels, there is an additional change in total marginal intermediation due to cross crowding in/out of private intermediation (i.e., via changes in permanent income) .

More specifically, for an income level below $z^{*}$ - where the tax rate remains unchanged - the change in the level of total intermediation reflects the cross crowding out effect $d^{c} M_{t}(z, \mathbf{s})$ only. For an income level above the band $\left[z^{*}, z^{*}+d z^{*}\right]$ - where the tax payment has increased - the total intermediation changes by $d^{o} M_{t}(z, \mathbf{s})+d^{c} M_{t}(z, \mathbf{s})$ with

$$
\begin{gathered}
d^{o} M_{t}(z, \mathbf{s})=\left(1-r_{t}^{o}(z, \mathbf{s})\right)\left(1-\tilde{P}_{t}^{\prime}\left(y^{z}, \mathbf{s}\right)\right) \delta \tau d z^{*}, \text { for } z \geq z^{*}+d z^{*} \\
d^{c} M_{t}(z, \mathbf{s})=d^{c} \tilde{P}_{t}\left(y^{0}, \mathbf{s}\right)+\delta \tau d z^{*} \int_{0}^{z} \frac{d^{c} \tilde{P}_{t}^{\prime}\left(y^{\tilde{z}}, \mathbf{s}\right)}{d T^{\prime}\left(z^{*}\right)}\left(1-T^{\prime}(\tilde{z})\right) d \tilde{z}, \text { for all } z
\end{gathered}
$$

where $d^{c} P_{t}\left(y^{0}, \mathbf{s}\right)$ denotes the change in the intercept of the private intermediation schedule due to cross crowding out. By integrating the changes in the total intermediation across all households, the aggregate change in the total intermediation in period $t, d \bar{M}_{t}^{a}$, is:

$$
\begin{aligned}
d \bar{M}_{t}^{a} & =\int_{z \geq z^{*}, \mathbf{s}} d^{o} M_{t}(z, \mathbf{s}) h(z) d \Phi(z, \mathbf{s})+\int d^{c} M_{t}(z, \mathbf{s}) d \Phi(z, \mathbf{s}) \\
& =\delta \tau d z^{*}\left(1-H\left(z^{*}\right)\right) \int\left(1-r_{t}^{o}\left(z^{*}, \mathbf{s}\right)\right)\left(1-\tilde{P}_{t}^{\prime}\left(y^{z^{*}}, \mathbf{s}\right)\right) d \Phi\left(\mathbf{s} \mid z^{*}\right)+\int d^{c} M_{t}(z, \mathbf{s}) d \Phi(z, \mathbf{s}) .
\end{aligned}
$$




\subsubsection{Behavioral Response of Labor Supply}

The increased marginal tax on an income band $\left[z^{*}, z^{*}+d z^{*}\right]$ affects the (before-tax) labor income via the labor supply through two channels: (i) the direct effects from an exogenous increase in the tax rate itself $\delta \tau$ and (ii) the indirect effects from the change in labor income along the given tax schedule by $d z$, which in turn results in the change in the marginal tax by $T^{\prime \prime}(z) d z$. The change in before-tax income is:

$$
d z=-z^{*} e\left(z^{*}\right) \frac{\delta \tau}{1-T^{\prime}+z^{*} e T^{\prime \prime}}
$$

where $e\left(z^{*}\right)$ is the Frisch elasticity of the labor supply at income level $z^{*}$. The change in total intermediation from these effects is:

$$
\begin{aligned}
& \int d z \cdot M_{t}^{\prime}\left(z^{*}, \mathbf{s}\right) d \Phi\left(\mathbf{s} \mid z^{*}\right) h\left(z^{*}\right) d z^{*} \\
= & -\int \frac{T^{\prime}\left(z^{*}\right)+\tilde{P}_{t}^{\prime}\left(y^{z^{*}}, \mathbf{s}\right)\left(1-T^{\prime}\left(z^{*}\right)\right)}{1-T^{\prime}+z^{*} e\left(z^{*}\right) T^{\prime \prime}} d \Phi\left(\mathbf{s} \mid z^{*}\right) z^{*} e\left(z^{*}\right) h\left(z^{*}\right) \delta \tau d z^{*} .
\end{aligned}
$$

As in Saez (2001), we introduce the virtual density $h^{*}(z)$ to simplify the presentation of the optimal tax formula where $h^{*}(z)$ is the density of incomes that would take place at $z$ if the tax schedule $T(\cdot)$ were replaced by the linear tax schedule tangent to $T(\cdot)$ at level $z$. When there is no income effect, Lemma 1 of Saez (2001) still applies.

Lemma 1 (Lemma 1 of Saez (2001)). For any regular tax schedule $T$ not necessarily optimal, the earnings function $z_{x}$ is non-decreasing and satisfies the following differential equation:

$$
\frac{\dot{z}_{x}}{z_{x}}=\frac{1+e}{x}-\dot{z}_{x} \frac{T_{(x)}^{\prime}}{1-T_{(x)}^{\prime}} e .
$$

Using Lemma 1 and the fact that $f(x)=h(z) \dot{z}_{x}=h^{*}(z) \dot{z}_{x}^{*}$ where $\dot{z}^{*}$ is the derivative when the linearized tax schedule is in place, we obtain: $\frac{h^{*}(z)}{1-T^{\prime}(z)}=\frac{h(z)}{1-T^{\prime}(z)+e z T^{\prime \prime}(z)}$. Then, the aggregate change in the total intermediation via the behavioral response of the labor supply, $d \bar{M}_{t}^{b}$, is:

$$
d \bar{M}_{t}^{b}=-\left\{\frac{T^{\prime}\left(z^{*}\right)}{1-T^{\prime}\left(z^{*}\right)}+\int \tilde{P}_{t}^{\prime}\left(y^{z^{*}}, \mathbf{s}\right) d \Phi\left(\mathbf{s} \mid z^{*}\right)\right\} z^{*} e\left(z^{*}\right) h^{*}\left(z^{*}\right) \delta \tau d z^{*}
$$

While the Frisch elasticity $e\left(z^{*}\right)$ may depend on the income level, we will focus on a constant Frisch elasticity $e$ below, for a simpler representation of the formula. 


\subsubsection{Optimal Tax Formula}

Upon the above tax reform, a household pays an extra amount of $d M_{t}(z, \mathbf{s})=d^{o} M_{t}(z, \mathbf{s})+d^{c} M_{t}(z, \mathbf{s})$ as a total intermediation in period $t$. Using the envelope theorem, this leads to the change in social welfare of:

$$
-\int d M_{t}(z, \mathbf{s}) G^{\prime}(u(z, \mathbf{s})) u^{\prime}(c(z, \mathbf{s})) d \Phi(z, \mathbf{s})
$$

Each period the increased (aggregate) total intermediation, $d \bar{M}_{t}=d \bar{M}_{t}^{a}+d \bar{M}_{t}^{b}$, will be rebated to all households in a lump-sum fashion, which results in the change in social welfare of: ${ }^{8}$

$$
d \bar{M}_{t} \int G^{\prime}(u(z, \mathbf{s})) u^{\prime}(c(z, \mathbf{s})) d \Phi(z, \mathbf{s}) .
$$

The overall change in social welfare from the tax reform is:

$d S W F=\sum_{t=0}^{\infty} \beta^{t} d \bar{M}_{t} \int G^{\prime}(u(z, \mathbf{s})) u^{\prime}(c(z, \mathbf{s})) d \Phi(z, \mathbf{s})-\sum_{t=0}^{\infty} \beta^{t} \int d M_{t}(z, \mathbf{s}) G^{\prime}(u(z, \mathbf{s})) u^{\prime}(c(z, \mathbf{s})) d \Phi(z, \mathbf{s})$.

A tax schedule $T(z)$ is optimal if $d S W F=0$ (no improvement in social welfare):

$$
\begin{aligned}
& \sum_{t=0}^{\infty} \beta^{t} d \bar{M}_{t}=\sum_{t=0}^{\infty} \beta^{t} \int d M_{t}(z, \mathbf{s}) g(z, \mathbf{s}) d \Phi(z, \mathbf{s}) \\
& \text { where } g(z, \mathbf{s})=\frac{G^{\prime}(u(z, \mathbf{s})) u^{\prime}(c(z, \mathbf{s}))}{A}, \quad A=\int G^{\prime}(u(z, \mathbf{s})) u^{\prime}(c(z, \mathbf{s})) d \Phi(z, \mathbf{s}) .
\end{aligned}
$$

By substituting out $d \bar{M}_{t}$ and $d M_{t}(z, \mathbf{s})$ and rearranging, we obtain the following optimal tax formula.

Proposition 2. Optimal marginal tax rate at income $z^{*}$ should satisfy the following formula :

$$
\frac{T^{\prime}\left(z^{*}\right)}{1-T^{\prime}\left(z^{*}\right)}=(1-\beta) \sum_{t=0}^{\infty} \beta^{t}\left[-\int \tilde{P}^{\prime}\left(y^{z^{*}}, \mathbf{s}\right) d \Phi\left(\mathbf{s} \mid z^{*}\right)+B_{t}\left(z^{*}\right)+C_{t}\left(z^{*}\right)\right]
$$

where

$$
\begin{aligned}
& B_{t}\left(z^{*}\right)=\frac{1}{e} \frac{1-H\left(z^{*}\right)}{z^{*} h^{*}\left(z^{*}\right)} \int_{z^{*}}^{\infty} \int\left(1-r_{t}^{o}\left(z^{*}, \mathbf{s}\right)\right)\left(1-\tilde{P}^{\prime}\left(y^{z^{*}}, \mathbf{s}\right)\right)(1-g(z, \mathbf{s})) d \Phi(\mathbf{s} \mid z) \frac{h(z)}{1-H\left(z^{*}\right)} d z \\
& C_{t}\left(z^{*}\right)=\frac{1}{e} \frac{1}{z^{*} h^{*}\left(z^{*}\right)} \int(1-g(z, \mathbf{s})) d^{c} P_{t}(z, \mathbf{s}) d \Phi(z, \mathbf{s}), \\
& \text { and } d^{c} P_{t}(z, \mathbf{s})=\left[\frac{d^{c} \tilde{P}_{t}\left(y^{0}, \mathbf{s}\right)}{\delta \tau d z^{*}}-\int_{0}^{z} r_{t}^{c}(\tilde{z}, \mathbf{s}) \frac{\left(1-\tilde{P}_{t}^{\prime}\left(y^{\tilde{z}}, \mathbf{s}\right)\right)\left(1-T^{\prime}(\tilde{z})\right)}{1-T^{\prime}\left(z^{*}\right)} d \tilde{z}\right] .
\end{aligned}
$$

\footnotetext{
${ }^{8}$ More precisely, the change in the aggregate total intermediation $d \bar{M}_{t}$ is the sum of the change in the aggregate tax $d \bar{T}$ and the change in the aggregate private intermediation $d \bar{P}$. The change in the aggregate tax $d \bar{T}$ is rebated back as a lump-sum transfer because we consider a revenue-neutral tax reform, and the change in the aggregate private intermediation $d \bar{P}$ is zero because we consider a pure insurance private market where net payments sum to zero $(\bar{P}=0)$.
} 
Note that the distributions are time invariant because we consider an economy starting from the steady state and the labor supply adjusts instantaneously (no wealth effect). However, private savings may adjust slowly over time, since asset holdings may change slowly. Thus, $r_{t}^{o}(\cdot)$ and $r_{t}^{c}(\cdot)$ can be time varying.

The following corollary shows that our optimal tax formula (1) nests Saez (2001), which is the formula when there is no private insurance.

Corollary 3. Without private intermediation, $P_{t}^{\prime}(\cdot)=r_{t}^{o}(\cdot)=r_{t}^{c}(\cdot)=0$ and $\Phi(z, \mathbf{s})=h(z)$. Then, our formula goes back to that in Saez (2001):

$$
\frac{T^{\prime}\left(z^{*}\right)}{1-T^{\prime}\left(z^{*}\right)}=\frac{1}{e} \frac{1-H\left(z^{*}\right)}{z^{*} h^{*}\left(z^{*}\right)} \int_{z^{*}}^{\infty}\left(1-\frac{G^{\prime}(u(z)) u^{\prime}(c(z))}{A}\right) \frac{h(z)}{1-H\left(z^{*}\right)} d z .
$$

The opposite is when full insurance can be achieved through private intermediation. In this case, there is no role of public insurance.

Corollary 4. Suppose that the private market is complete with fully spanned state-contingent assets. Then, the optimal tax rate is zero: $T^{\prime}(z)=0, \forall z$.

Proof Consider a tax reform for a given tax schedule $T(z)$ such that $T^{\prime}(z)=0$ for all $z$. Since the market is complete, the consumption allocation under the given tax schedule is constant across states, and thus $G^{\prime}(u(z, \mathbf{s})) u^{\prime}(c(z, \mathbf{s}))=A, \forall(z, \mathbf{s})$, for some constant $A$. Then the change in social welfare due to tax reform is

$$
d S W F=\sum_{t=0}^{\infty} \beta^{t} d \bar{M}_{t} \cdot A-\sum_{t=0}^{\infty} \beta^{t} A \int d M_{t}(z, \mathbf{s}) d \Phi(z, \mathbf{s})=0,
$$

where the second equality is from $d \bar{M}_{t}=\int d M_{t}(z, \mathbf{s}) d \Phi(z, \mathbf{s})$. Thus zero tax is optimal.

If the market is incomplete, however, the optimal tax formula depends on additional statistics on households' private intermediation which we will discuss in detail below. Before discussing the role of the private market, we lay out the conditions under which the total insurance generated by setting the optimal tax with a private market becomes identical to that without a private market.

\subsubsection{Special Case : Equivalence Result}

We investigate the conditions under which the sum of private and (optimal) public insurance in the presence of a private market is the same as the amount of optimal public insurance without a private market. Under these conditions, the allocations of the two economies will be identical. 
Proposition 5. Suppose that the private market structure has the following properties:

(i) the net payment schedule of the private market $P_{t}$ is time invariant and depends on current earnings $z$ only: $P_{t}(z, \mathbf{s} ; T)=P(z ; T)$, and

(ii) the elasticity of cross crowding in/out in the marginal private intermediation is zero:

$$
r^{c}(z)=-\frac{d^{c} \log \left(1-\tilde{P}^{\prime}\left(y^{z}\right)\right)}{d \log \left(1-T^{\prime}(z)\right)}=0, \quad \forall z
$$

Then, the allocation under the optimal tax with a private market is equivalent to that under the optimal tax without a private market, and the optimal tax rate satisfies:

$$
\frac{T^{\prime}\left(z^{*}\right)}{1-T^{\prime}\left(z^{*}\right)}=-\tilde{P}^{\prime}\left(y^{z^{*}}\right)+\frac{1-r^{o}\left(z^{*}\right)}{e_{z, 1-T^{\prime}}} \frac{1-H\left(z^{*}\right)}{z^{*} h^{*}\left(z^{*}\right)}\left(1-\tilde{P}^{\prime}\left(y^{z^{*}}\right)\right) \int_{z^{*}}^{\infty}(1-g(z)) \frac{h(z)}{1-H\left(z^{*}\right)} d z
$$

Proof Since the private market payment schedule $P$ depends only on current earnings $z$, the first term of the tax formula (1) boils down to $-\tilde{P}^{\prime}\left(y^{z^{*}}\right)$. The condition $(i)$ of the private market payment schedule implies that the elasticity of own crowding out in the marginal private intermediation is time invariant and depends only on current earnings $z$ :

$$
r_{t}^{o}(z)=-\frac{d^{o} \log \left(1-\tilde{P}^{\prime}\left(y^{z}\right)\right)}{d \log \left(1-T^{\prime}(z)\right)}=r^{o}(z), \quad \forall t, \forall z .
$$

It is straightforward to see that the third term of the tax formula (1) is zero by the condition (ii) of the private market payment schedule. Thus, we get the optimal tax formula (3).

We now show that an optimal allocation in an economy without a private market - allocation under the Saez tax formula (2) - can be reproduced in an economy with a private market. For this, we only need to show that the optimal total marginal intermediation $M^{\prime}(z)=T^{\prime}(z)+\tilde{P}^{\prime}\left(y^{z}\right)(1-$ $\left.T^{\prime}(z)\right)$ generated by setting the tax rate to (3) is equal to the optimal tax formula without a private market (2). We can rewrite the formula (3) by combining the terms associated with the marginal private intermediation with the marginal tax rate:

$$
\frac{M^{\prime}\left(z^{*}\right)}{1-M^{\prime}\left(z^{*}\right)}=\frac{T^{\prime}\left(z^{*}\right)+\tilde{P}^{\prime}\left(y^{z^{*}}\right)\left(1-T^{\prime}\left(z^{*}\right)\right)}{\left(1-T^{\prime}\left(z^{*}\right)\right)\left(1-\tilde{P}^{\prime}\left(y^{z^{*}}\right)\right)}=\frac{1-r^{o}\left(z^{*}\right)}{e_{z, 1-T^{\prime}}} \frac{1-H\left(z^{*}\right)}{z^{*} h^{*}\left(z^{*}\right)} \int_{z^{*}}^{\infty}(1-g(z)) \frac{h(z)}{1-H\left(z^{*}\right)} d z .
$$

By exploiting $\frac{d\left(1-M^{\prime}\right)}{1-M^{\prime}}=\left(1-r^{o}\right) \frac{d\left(1-T^{\prime}\right)}{1-T^{\prime}}$, we obtain the following relationship:

$$
e_{z, 1-M^{\prime}}\left(z^{*}\right)=\frac{e_{z, 1-T^{\prime}}\left(z^{*}\right)}{1-r^{o}\left(z^{*}\right)}
$$


and thus the sum of private and public insurance $M^{\prime}(z)$ satisfies the standard formula without a private market.

Whether the presence of a private market can improve or reduce total insurance depends on the tools the government has and the frictions it faces. As we discussed in corollary 4, if the market is complete with fully spanned state-contingent assets, then the market provides the best insurance and there is no role for government insurance. On the other hand, if the financial instrument available for private intermediation is limited, the existence of a private market may lower social welfare because the private intermediation may not necessarily be aligned with government policies. Proposition 5 shows that if the private market and the government have identical tools and the private market schedule has a one-to-one relationship with the tax schedule, the sum of private and (optimal) public insurance is equivalent to the amount of public insurance from the standard formula without private insurance, as in Saez (2001). Since the government would like to achieve the optimal total insurance, the total marginal intermediation $M^{\prime}(z)$ should be set according to

the standard formula. Note that the relevant elasticity becomes $e_{z, 1-M^{\prime}}\left(z^{*}\right)=\frac{e_{z, 1-T^{\prime}}\left(z^{*}\right)}{1-r^{o}\left(z^{*}\right)}$ because a $1 \%$ increase in $1-T^{\prime}$ (without private savings) is equivalent to a $\left(1-r^{o}\right) \%$ increase in $1-M^{\prime}$.

One example that satisfies these conditions is Chetty and Saez (2010), where both the government and the private market have the same tool: a static linear marginal tax (and savings) rate with lump-sum transfer. Since there is only one tax rate, there is no cross crowding in/out effect. Thus, Chetty and Saez (2010) can be viewed as a special case that fits our equivalence result in Proposition 5 .

\subsubsection{Role of Private Insurance Market}

One of the nice features of Saez (2001)'s formula (2) is that the optimal tax schedule can be expressed in terms of "sufficient" statistics. The optimal tax rate $\left(T^{\prime}\right)$ is decreasing in (i) the Frisch elasticities of the labor supply, $e$, (ii) the hazard rate of the income distributions, $\frac{z^{*} h\left(z^{*}\right)}{1-H\left(z^{*}\right)}$, and (iii) the average social marginal welfare weight of income above $z^{*}, E\left[g(z, \mathbf{s}) \mid z \geq z^{*}\right]$. A larger Frisch elasticity implies a bigger efficiency cost from distorting the labor supply and thus the tax rate is decreasing in $e$. The cost of distortion is proportional to the number of workers $\left(z^{*} h\left(z^{*}\right)\right)$, while the revenue gain from the tax increase is proportional to the fraction of income higher than $z^{*}$ : $1-H\left(z^{*}\right)$. Thus, the optimal tax rate is decreasing in the hazard rate $\left(\frac{z^{*} h\left(z^{*}\right)}{1-H\left(z^{*}\right)}\right)$. The marginal social welfare weight $g(z, \mathbf{s})$ measures the relative value of an additional dollar of consumption 
at each state $(z, \mathbf{s})$ from the perspective of the government. A larger social welfare weight on households who will pay extra tax as a result of tax reform $\left(E\left[g(z, \mathbf{s}) \mid z \geq z^{*}\right]\right)$ leads to a lower tax rate. These channels are still operative in formula (1).

However, in the presence of a private insurance market, the standard sufficient statistics are not sufficient to pin down the optimal tax schedule. The optimal tax schedule also depends on how the private insurance market interacts with public savings, such as marginal private savings $\tilde{P}^{\prime}(\cdot)$ and crowding in/out elasticities, $r_{t}^{o}(\cdot)$ and $r_{t}^{c}(\cdot)$.

To better understand the role of private insurance in the optimal tax rate, we re-arrange the formula as follows (by combining the terms related to crowding in/out of private insurance):

$$
\begin{aligned}
\frac{T^{\prime}\left(z^{*}\right)}{1-T^{\prime}\left(z^{*}\right)}= & (1-\beta) \sum_{t=0}^{\infty} \beta^{t}\left[-\int \tilde{P}^{\prime}\left(y^{z^{*}}, \mathbf{s}\right) d \Phi\left(\mathbf{s} \mid z^{*}\right)\right. \\
& +\frac{1}{e} \frac{1-H\left(z^{*}\right)}{z^{*} h^{*}\left(z^{*}\right)} \int_{z^{*}}^{\infty} \int\left(1-\tilde{P}^{\prime}\left(y^{z^{*}}, \mathbf{s}\right)\right)(1-g(z, \mathbf{s})) d \Phi(\mathbf{s} \mid z) \frac{h(z)}{1-H\left(z^{*}\right)} d z \\
& \left.+\frac{1}{e} \frac{1}{z^{*} h^{*}\left(z^{*}\right)} \int \frac{1}{e} \frac{1}{z^{*} h^{*}\left(z^{*}\right)} \int(1-g(z, \mathbf{s})) \frac{d \tilde{P}_{t}\left(y^{z}, \mathbf{s}\right)}{\delta \tau d z^{*}} d \Phi(z, \mathbf{s})\right], \\
\text { where } \quad & d \tilde{P}_{t}\left(y^{z}, \mathbf{s}\right)=\underbrace{-r_{t}^{o}\left(z^{*}, \mathbf{s}\right)\left(1-\tilde{P}_{t}^{\prime}\left(y^{z^{*}}, \mathbf{s}\right)\right) \delta \tau d z^{*}}_{=d^{o} \tilde{P}_{t}\left(y^{z}, \mathbf{s}\right)}+\underbrace{d^{c} M_{t}(z, \mathbf{s})}_{=d^{c} \tilde{P}_{t}\left(y^{z}, \mathbf{s}\right)}
\end{aligned}
$$

The first term in the bracket on the right-hand side, $-\int \tilde{P}^{\prime}\left(z^{*}-T\left(z^{*}\right), \mathbf{s}\right) d \Phi\left(\mathbf{s} \mid z^{*}\right)$, reflects the fact that the two types (public and private) of insurance are substitutes. Thus, the optimal marginal tax is decreasing in marginal private savings $\tilde{P}^{\prime}(\cdot)$.

The second term is identical to the original formula in Saez (2001)-Equation (2) above-except for two aspects: (i) the Saez (2001) formula is now multiplied by $\left(1-\tilde{P}^{\prime}\left(y^{z^{*}}, \mathbf{s}\right)\right)$ and (ii) the integration is now over the cross-sectional distribution of other state variables as well as that of incomes: $\Phi(z, \mathbf{s})$. The original Saez effects can be either amplified or mitigated depending on (i) the sign of the marginal private savings $\tilde{P}^{\prime}$ and (ii) the shape of $\Phi(z, \mathbf{s})$. The welfare effect of tax reform is measured in terms of the value of additional consumption and thus depends on the marginal propensity to consume. For households that would like to borrow at the margin - whose marginal private saving is negative - one unit of additional disposable income is highly valuable as the marginal propensity to consume $\left(1-\tilde{P}^{\prime}\right)$ is greater than one. Thus the Saez effects are amplified. On the other hand, when the marginal private saving $\tilde{P}^{\prime}$ is positive, a one unit increase in disposable income increases consumption by less than one $\left(\left(1-\tilde{P}^{\prime}\right)<1\right)$, and thus the Saez 
effects are mitigated. The shape of $\Phi(z, \mathbf{s})$ can also amplify (mitigate) the Saez effects through the increase (decrease) in consumption inequality because the social welfare function is concave.

The third term in the bracket reflects whether the tax reform is aligned with the change in the cross-sectional pattern of private savings. More precisely, this term captures the interaction of "progressivity" between public and private insurance. To see this, note that the integral in the third term is:

$$
\int\left\{(1-g(z, \mathbf{s})) \cdot d \tilde{P}_{t}\left(y^{z}, \mathbf{s}\right)\right\} d \Phi(z, \mathbf{s})=\operatorname{Cov}\left(1-g(z, \mathbf{s}), d \tilde{P}_{t}\left(y^{z}, \mathbf{s}\right)\right)
$$

where $g(z, \mathbf{s})=\frac{G^{\prime}(u(z, \mathbf{s})) u^{\prime}(c(z, \mathbf{s}))}{A}$ is the marginal social welfare weights. In general (e.g., under the utilitarian social welfare function), the marginal social welfare weight decreases with income. ${ }^{9}$ Then, $1-g(z, \mathbf{s})$ increases (from a negative to a positive value) with income. The term $d \tilde{P}_{t}\left(y^{z}, \mathbf{s}\right.$ ) reflects the response of private savings to a tax reform (crowding in or out). The optimal marginal tax is high when the cross-sectional covariance, $\operatorname{Cov}\left(1-g(z, \mathbf{s}), d \tilde{P}_{t}\left(y^{z}, \mathbf{s}\right)\right)$, is large. That is, a progressive tax reform is desirable when such reform makes the private intermediation more progressive. To be more specific, consider a marginal tax increase-i.e., the tax schedule becomes more progressive. If $d \tilde{P}_{t}\left(y^{z}, \mathbf{s}\right)$ increases with income levels, the private intermediation becomes more "progressive" (the rich save more in response to a tax reform). This will generate a positive $\operatorname{Cov}\left(1-g(z, \mathbf{s}), d \tilde{P}_{t}\left(y^{z}, \mathbf{s}\right)\right)$, which in turn results in a high optimal marginal tax. In other words, a tax reform is effective because private intermediation is aligned with the direction of the reform. On the other hand, if private savings become "regressive" in response to a tax increase (the poor save more), the tax reform is not effective because the progressive tax (for insurance) is partially undone by a regressive private intermediation.

\subsection{Rewriting Optimal Formula w.r.t. Productivity Distribution}

The optimal tax formula (4) involves an endogenous income distribution. For the quantitative analysis below, it is useful to express the formula with respect to the exogenous productivity distribution.

We know that income density and the skill density are related through the equation $h^{*}(z) \dot{z}_{x}^{*}=$ $f(x)$ and using lemma 1 , we get

$$
f(x)=(1+e) \frac{z_{x}}{x} h^{*}\left(z_{x}\right)
$$

\footnotetext{
${ }^{9}$ The welfare weights would decrease rapidly under a social welfare function that has a strong preference for redistribution $G^{\prime \prime}<0$.
} 
With a slight abuse of notation we denote the joint distribution of skill and other state variables by $\Phi(x, \mathbf{s})$ and its density by $\phi(x, \mathbf{s})$, where $\phi(x, \mathbf{s})=\phi(\mathbf{s} \mid x) f(x)$. By combining (6) with (4), we obtain the following proposition.

Proposition 6. The optimal marginal tax rate of the government should satisfy the following:

$$
\begin{aligned}
& \frac{T^{\prime}\left(x l_{x}\right)}{1-T^{\prime}\left(x l_{x}\right)}=(1-\beta) \sum_{t=0}^{\infty} \beta^{t}\left[-\int \tilde{P}^{\prime}\left(x l_{x}, \mathbf{s}\right) d \Phi(\mathbf{s} \mid x)\right. \\
& \quad+\frac{1-F(x)}{x f(x)}\left(1+\frac{1}{e}\right) \int_{x}^{\infty} \int(1-g(m, \mathbf{s}))\left(1-\tilde{P}^{\prime}\left(y_{x}\right), \mathbf{s}\right) d \Phi(\mathbf{s} \mid m) \frac{f(m)}{1-F(x)} d m \\
& \left.\quad+\frac{1}{x f(x)}\left(1+\frac{1}{e}\right) \int(1-g(m, \mathbf{s})) \frac{d \tilde{P}_{t}\left(y^{m}, \mathbf{s}\right)}{\delta \tau d z^{*}} d \Phi(m, \mathbf{s})\right]
\end{aligned}
$$

where $g(m, \mathbf{s})=\frac{G^{\prime}(u(m, \mathbf{s})) u^{\prime}(c(m, \mathbf{s}))}{A}$.

\section{A Quantitative Analysis}

According to our formula (1), the optimal tax schedule can be completely characterized by the standard sufficient statistics (such as the Frisch elasticity of the labor supply, marginal social welfare weights, and the productivity distribution) and households' savings behavior (such as marginal

private intermediation $P^{\prime}(\cdot)$ and crowding in/out elasticities, $r_{t}^{o}(\cdot)$ and $\left.r_{t}^{c}(\cdot)\right)$. The marginal private intermediation may be obtained from cross-sectional data. However, the crowding in/out elasticities are very difficult to measure empirically because it would require natural experiments of households at various income levels. In this section, we obtain these statistics from an incomplete-markets general equilibrium model that is calibrated to reproduce the productivity distribution of the U.S economy.

\subsection{Model Economy: Huggett (1993)}

We consider a variant of Huggett (1993) for two reasons. First, it is widely used in many macroeconomic analyses. Second, the analytical formula requires the aggregate private intermediation to be zero $\left(\int P=0\right)$ : a pure insurance market. In Huggett (1993)'s economy, the private savings market is incomplete in two senses: (i) the only asset available for private insurance is a state noncontingent bond $a_{t}$, and (ii) there is an exogenous borrowing limit: $a_{t+1} \geq \underline{a}(<0)$. 
In this economy, the individual state variables are asset holdings $a$ and productivity $x$. The consumption of a worker with asset $a$ and productivity $x$ is:

$$
c(a, x)=x l-T(x l)+(1+r) a-a^{\prime}(a, x) .
$$

where $a^{\prime}$ is the asset holdings in the next period. Private savings of a worker with asset $a$ and productivity $x$ is $P(a, x l)=x l-T(x l)-c(a, x)=a^{\prime}(a, x)-(1+r) a$. The aggregate private savings sum to zero in equilibrium: $\int a^{\prime}=0$.

In our model, the government spends its tax revenue on purchasing goods $E$ (which does not enter into the households' utility) as well as a lump-sum transfer. When we consider a revenue-neutral tax reform, the government purchase $E$ remains unchanged. The government budget is:

$$
\int T(z) h(z) d z=\bar{E}
$$

We assume that productivity $x$ can take values from a finite set of $N$ grid points $\left\{x_{1}, x_{2}, \cdots, x_{N}\right\}$ and follows a Markov process that has an invariant distribution. We approximate an optimal nonlinear tax and private intermediation with a piecewise-linear so that:

$$
\begin{aligned}
& T(z)=T(0)+\sum_{k=1}^{i-1} T_{k}^{\prime}\left(z_{x_{k}}-z_{x_{k-1}}\right)+T_{i}^{\prime}\left(z-z_{x_{i-1}}\right), \quad z_{x_{i-1}}<z \leq z_{x_{i}}, \\
& \tilde{P}(y)=\tilde{P}\left(y^{0}\right)+\sum_{k=1}^{i-1} \tilde{P}_{k}^{\prime}\left(y_{x_{k}}-y_{x_{k-1}}\right)+\tilde{P}_{i}^{\prime}\left(y-y_{x_{i-1}}\right), \quad y_{x_{i-1}}<y \leq y_{x_{i}},
\end{aligned}
$$

where $z_{x_{-1}}=0$ and $y_{x_{-1}}=y^{0}=-T(0)$. Consider a tax reform that increases the marginal tax rate on each grid point $T_{i}^{\prime}, i=1, \cdots, N$. For each tax reform, we compute a new equilibrium based on which an alternative tax rate is proposed according to our optimal tax formula. If the tax reform for every grid point no longer improves social welfare, the optimal tax schedule is found. We only compute the change in the steady-state welfare. ${ }^{10}$ The parameter values for our quantitative model are calibrated as follows.

\subsection{Calibration}

Preferences, Government Expenditure, and Borrowing Constraints

\footnotetext{
${ }^{10}$ If the adjustment in the asset market is fast enough, then the steady-state comparison will be close to the comparison taking into account the transition path.
} 
For our benchmark economy, we use the relative risk aversion $(\sigma)$ of 1.5 and a Frisch elasticity of labor supply $(e)$ of 0.5 . We choose the discount factor $(\beta)$ so that the rate of return from asset holdings is $4 \%$ in the steady state. The government purchase $\bar{E}$ is chosen so that the government expenditure-GDP ratio is 0.188 under the current U.S. income tax schedule (approximated by a log-linear functional form: $T(z)=z-\lambda z^{1-\tau}$ ) as in Heathcote, Storesletten, and Violante (2014)). ${ }^{11}$ The exogenous borrowing constraint $(\underline{a}=-86.87)$ is set to the average earnings of our model economy under the current U.S. tax schedule. ${ }^{12}$ Under this borrowing limit, $9.7 \%$ of households are credit-constrained in the steady state. Finally, we assume that the social welfare function is utilitarian: $G($.$) is linear. Table 1$ summarizes the parameter values in our benchmark case. In Section 5, we consider various specifications of the model economy that differ with respect to the relative risk aversion, Frisch elasticity, borrowing constraints, and the shape of income distribution.

Table 1: Benchmark Parameter Values

\begin{tabular}{c|l}
\hline \hline Parameter & Description \\
\hline $\begin{array}{c}\sigma=1.5 \\
\beta=0.9032\end{array}$ & Relative Risk Aversion \\
$\gamma=0.5$ & Fiscount Factor \\
$\underline{a}=-86.87$ & Borrowing Constraint \\
$\frac{\bar{E}}{Y}=0.181$ & Government Expenditure to GDP Ratio under U.S. Tax \\
$G^{\prime \prime}(\cdot)=0$ & Utilitarian Social Welfare Function \\
$\rho_{x}=0.92$ & Persistence of Log Productivity (before modification) \\
$\sigma_{x}=0.561$ & S.D. of Log Productivity \\
$\frac{x f(x)}{1-F(x)}=2$ & Hazard Rate at Top 5\% of Wage (Income) Distribution \\
\hline \hline
\end{tabular}

\section{Productivity Process}

As shown in formula (4), the shape of the income distribution (which is dictated by the stochastic process of a productivity shock under our preferences with no wealth effect in the labor supply) is

\footnotetext{
${ }^{11}$ Given the estimated value for the progressivity, $\tau^{U S}=0.161$ from Heathcote, Storesletten, and Violante (2014), we set $\lambda$ to match the government expenditure-GDP ratio $\left(\frac{\bar{E}}{Y}\right)$.

${ }^{12}$ This is largely in line with consumer credit card limits (which is around $50 \%-100 \%$ of average earnings) in the data. For example, according to Narajabad (2012), based on the 2004 Survey of Consumer Finances data, the mean credit limit of U.S. households is $\$ 15,223$ measured in 1989 dollars.
} 
crucial for the optimal marginal tax schedule. We generate an empirically plausible distribution of productivity as follows. Consider an $\mathrm{AR}(1)$ process for log productivity $x$ :

$$
\ln x^{\prime}=(1-\rho) \mu+\rho \cdot \ln x+\sigma_{\epsilon} \epsilon^{\prime}
$$

where $\epsilon$ is distributed normally with mean zero and variance one. The cross-sectional standard deviation of $\ln x$ is $\sigma_{x}=\frac{\sigma_{\epsilon}}{\sqrt{1-\rho^{2}}}$. While this process leads to stationary log-normal distributions of productivity and earnings, it is well known that the actual distributions of productivity (wages) and earnings have much fatter tails than a log-normal distribution. ${ }^{13}$

We modify the Markov transition probability matrix to generate a fatter tail as follows. First, we set the persistence of the productivity shock to be $\rho=0.92$ following Floden and Linde (2001), which is based on PSID wages and largely consistent with other estimates in the literature. We obtain a transition matrix of $x$ in a discrete space using the Tauchen (1986) method, with $N=10$ states and $\left(\mu, \sigma_{x}\right)=(2.757,0.5611)$, which are Mankiw, Weinzierl, and Yagan's (2009) estimates from the U.S. wage distribution in 2007. We set the end points of the grid at $\left(x_{1}, x_{N}\right)=\left(\exp \left(\mu-3.4 \sigma_{x}\right), \exp \left(\mu+3.4 \sigma_{x}\right)\right) .{ }^{14}$ Second, in order to generate a fat right tail, we increase the transition probability $\pi\left(x^{\prime} \mid x\right)$ of the highest 3 grids so that the hazard rate of the stationary distribution is $\frac{x f(x)}{1-F(x)}=2$ for the top $5 \%$ of productivities. This hazard rate of 2 for the top 5\% is based on the empirical wage distribution in Mankiw, Weinzierl, and Yagan (2009). Third, we also increase the transition probability of the lowest grid, $\pi\left(x_{1} \mid x\right)$, so that the stationary distribution has a little bit fatter left tail as in Mankiw, Weinzierl, and Yagan (2009) ${ }^{15}$ As Figure 1 shows, the hazard rates of the productivity distribution from our model almost exactly matches those in the wage distribution in the data from Mankiw, Weinzierl, and Yagan (2009). In Section 5, we also study the model economy under a simple log-normal distribution of productivity to examine the impact of fat tails.

\section{Productivity, Income, and Asset Distributions}

Figures 2 and 3 show the stationary distributions of productivity and (labor) income, respectively, from our stochastic process of $x$. The productivity distribution exhibits fatter tails (at both ends)

\footnotetext{
${ }^{13}$ Saez (2001) and Heathcote, Storesletten, and Violante (2014) estimate the earnings distribution and use tax data to obtain the underlying skill distribution, while Mankiw, Weinzierl, and Yagan (2009) use the wage distribution as a proxy for the productivity distribution.

${ }^{14}$ We set the highest grid point to 3.4 standard deviations of log-normal so that the highest productivity is the top $1 \%$ of the productivity of distribution in Mankiw, Weinzierl, and Yagan (2009).

${ }^{15}$ The bottom tail of the productivity distribution should take into account disabled workers or those not employed.
} 
Figure 1: Hazard Rates of Wage (Productivity)

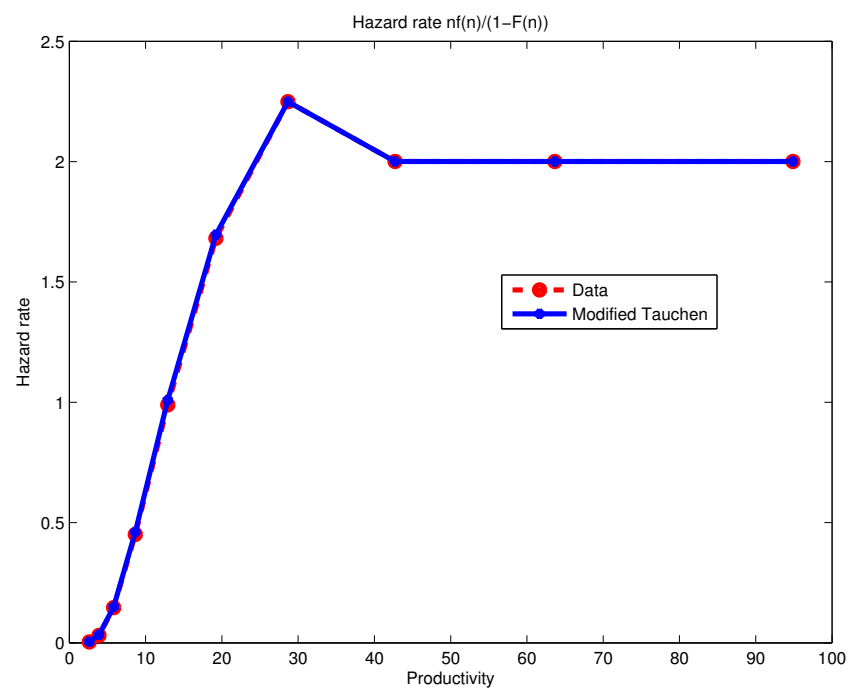

Note: The hazard rates are from Mankiw, Weinzierl, and Yagan (2009).

than a log-normal distribution, as we modified the transition probability matrix described above. With no wealth effect in the labor supply, the shape of the income distribution is essentially identical to that of productivity. Figure 4 shows the asset distribution of the model under the current U.S. tax system (approximated by the HSV functional form). As we discussed above, we set the borrowing constraint so that the fraction of credit-constrained households is about $10 \%$. It is well known that the asset distribution generated by a Huggett-style model economy cannot successfully match a large wealth inequality in the data. Moreover, in our model with a pure insurance market, the aggregate asset holdings always sum to zero in equilibrium, which requires a large fraction of households to have negative asset holdings. 
Figure 2: Productivity (Wage) Distribution

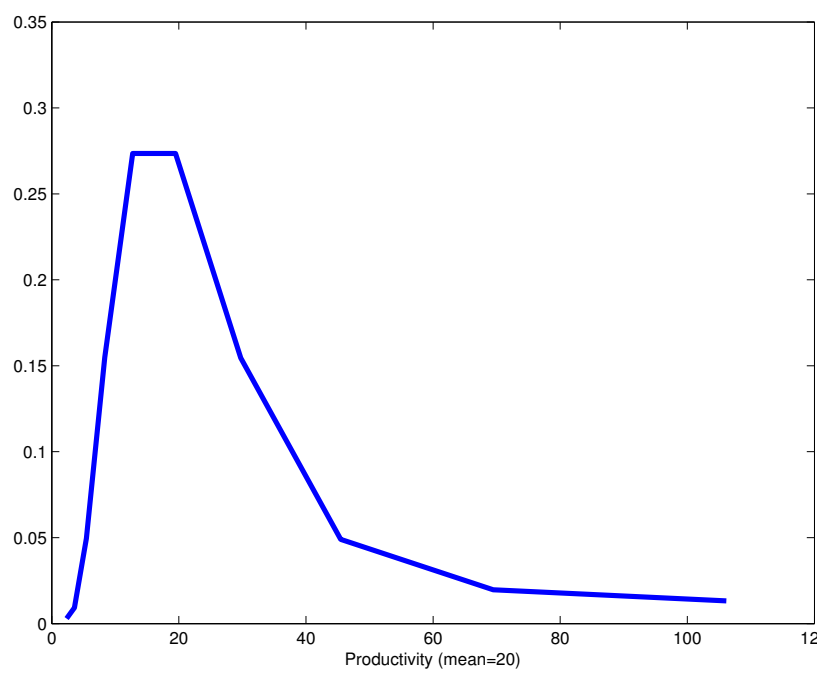

Figure 3: Income Distribution

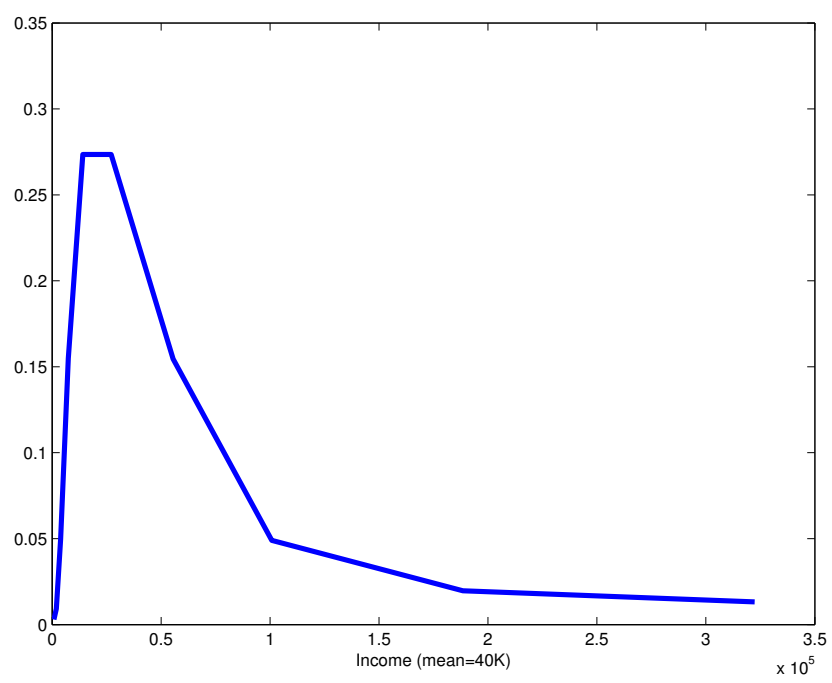

Figure 4: Asset Distribution under Current U.S. Tax Schedule

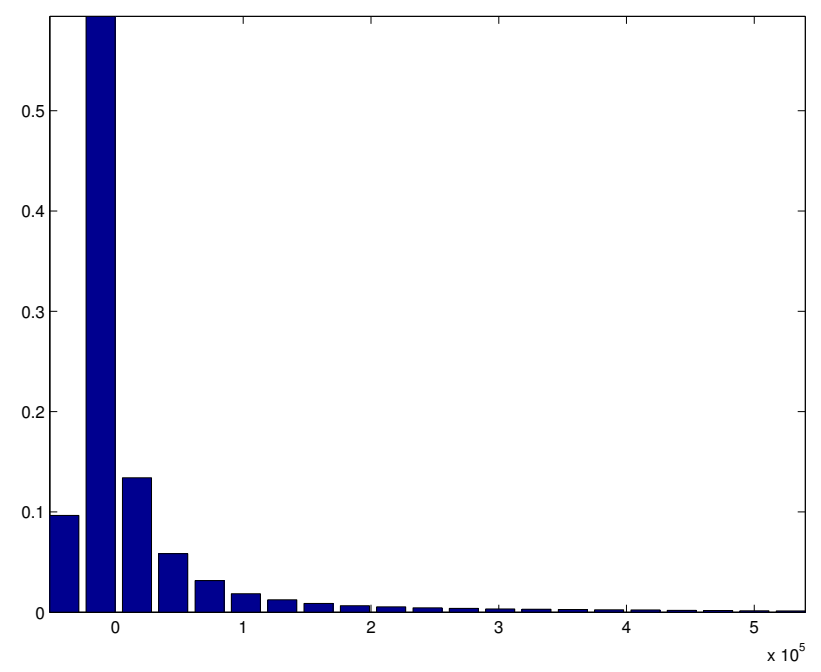




\subsection{Quantitative Results}

Figures 5 and 6 show the optimal marginal tax schedule across productivity and income, respectively, with and without a private insurance market. We normalize the units of quantities in our model so that the average productivity (wage) is $\$ 20$ and the average labor income is $\$ 40,000$ (comparable to those in 2015 in the U.S.). Without a private insurance market (dotted line), the optimal marginal tax schedule exhibits a well-known U-shape as in the standard Mirrleesian taxation literature. High marginal tax rates at the very low income levels indicate that net transfers to low income households should quickly phase out. As seen in Figure 1, the hazard rate of productivity sharply increases, implying that the cost of distorting the labor supply quickly increases (relative to the benefit): the optimal marginal tax rate should start decreasing with income. As income increases, the marginal social welfare weight gradually diminishes-which eventually becomes a dominant factor and results in a higher marginal tax at the high income group.

Figure 5: Optimal Marginal Tax Rate by Productivity Figure 6: Optimal Marginal Tax Rate by Income
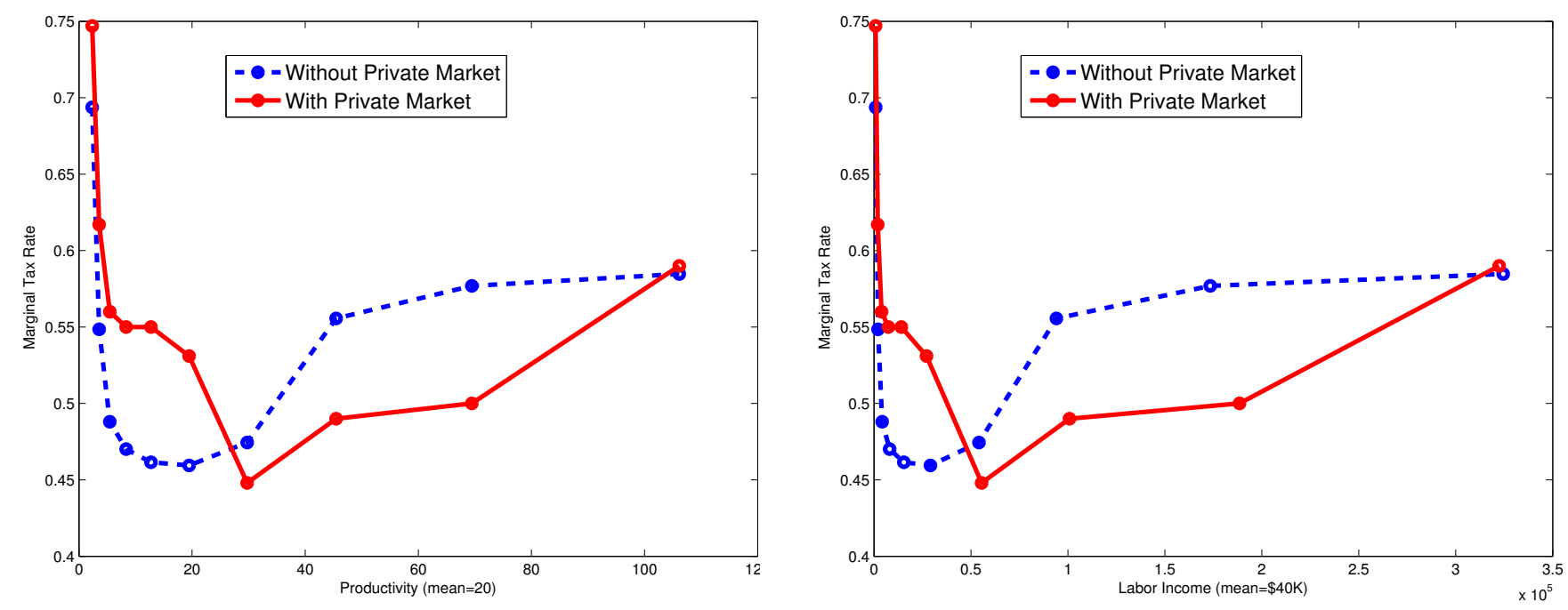

While the same driving forces are operative in an economy with a private insurance market, there are additional factors that make the optimal tax schedule different from that without a private insurance market. Looking at Figures 5 and 6 again, the optimal tax rates in the presence of private insurance (solid line) are higher than those without a private market (dotted line) at the low and middle income group (wage rates less than $\$ 25$ ). For the upper-middle and high income group (wage rates between $\$ 25$ and $\$ 100$ ), the optimal tax rates are higher than those without a private insurance. For the income group at the top (wage rates above $\$ 100$, which is approximately 
the 95 th percentile of the distribution), the tax rates with and without private insurance are similar.

We now examine the factors that account for the difference in optimal tax rates with and without private insurance in detail. Recall that the optimal tax formula in the presence of private insurance consists of three terms:

$$
\begin{aligned}
\frac{T^{\prime}\left(z^{*}\right)}{1-T^{\prime}\left(z^{*}\right)}= & -E\left[\tilde{P}^{\prime}\left(z^{*}-T\left(z^{*}\right), a\right) \mid z^{*}\right] \\
& +\frac{1-H\left(z^{*}\right)}{z^{*} h\left(z^{*}\right)} \frac{1}{e} E\left[(1-g(z, a))\left(1-\tilde{P}^{\prime}\left(y^{z}, a\right)\right) \mid z \geq z^{*}\right] \\
& \left.+\frac{1}{z^{*} h\left(z^{*}\right)} \frac{1}{e} E[(1-g(z, a))) \frac{d \tilde{P}\left(y^{z}, a\right)}{\delta \tau d z^{*}}\right] .
\end{aligned}
$$

Comparing our optimal tax formula to that of Saez (2001), the difference between the two formulas is made up of three components. The first component simply reflects the fact that private savings and government tax/transfer are substitutes in insuring against future income uncertainty - the first line in our formula $\left(-\tilde{P}^{\prime}\right)$. The second component is the difference between the second term in our formula and the original Saez formula - i.e., "dynamic Saez vs. static Saez," the multiplying factor in the second line $\left(1-\tilde{P}^{\prime}\right)$. The third component reflects the fact that a tax reform is more effective when the response of private savings is aligned with such reform - the last term in our formula $\left(E\left[(1-g) \frac{d \tilde{P}}{\delta \tau d z^{*}}\right]\right)$.

The sign and magnitude of these three components are determined by marginal private savings (MPS) and the cross-sectional pattern of crowding in/out of private savings. In the first term, a higher MPS leads to a lower marginal tax because they are substitutes in insuring against future income uncertainty. In the second term, the Saez effects are amplified or mitigated, depending on the sign of MPS. The shape of the cross-sectional distribution of MPS also matters for the second as well as the third component in the formula. In the incomplete-markets model, the asset distribution is dispersed (compared to the income distribution), which leads to a larger dispersion in consumption and $1-g$ (than in the economy without private savings). Thus, the integrals in the second and third terms become larger than those in the economy without private savings. In the third term, the cross-sectional response of crowding in/out of private savings determines whether the response of private savings is aligned with a tax reform. If an increase in marginal tax makes private savings more progressive - i.e., crowds out savings for the poor and crowds in savings for the rich - the third component is positive and large. Such a tax reform (progressive tax) is more effective. 
Figure 7 plots each of these three components. Since the magnitude of the first and second terms are huge at the very low productivity level, we plot these terms separately in two productivity groups: productivity below $\$ 8$ and above.

Figure 7: Decomposition of the Difference in $\frac{T^{\prime}}{1-T^{\prime}}$ with and without private insurance
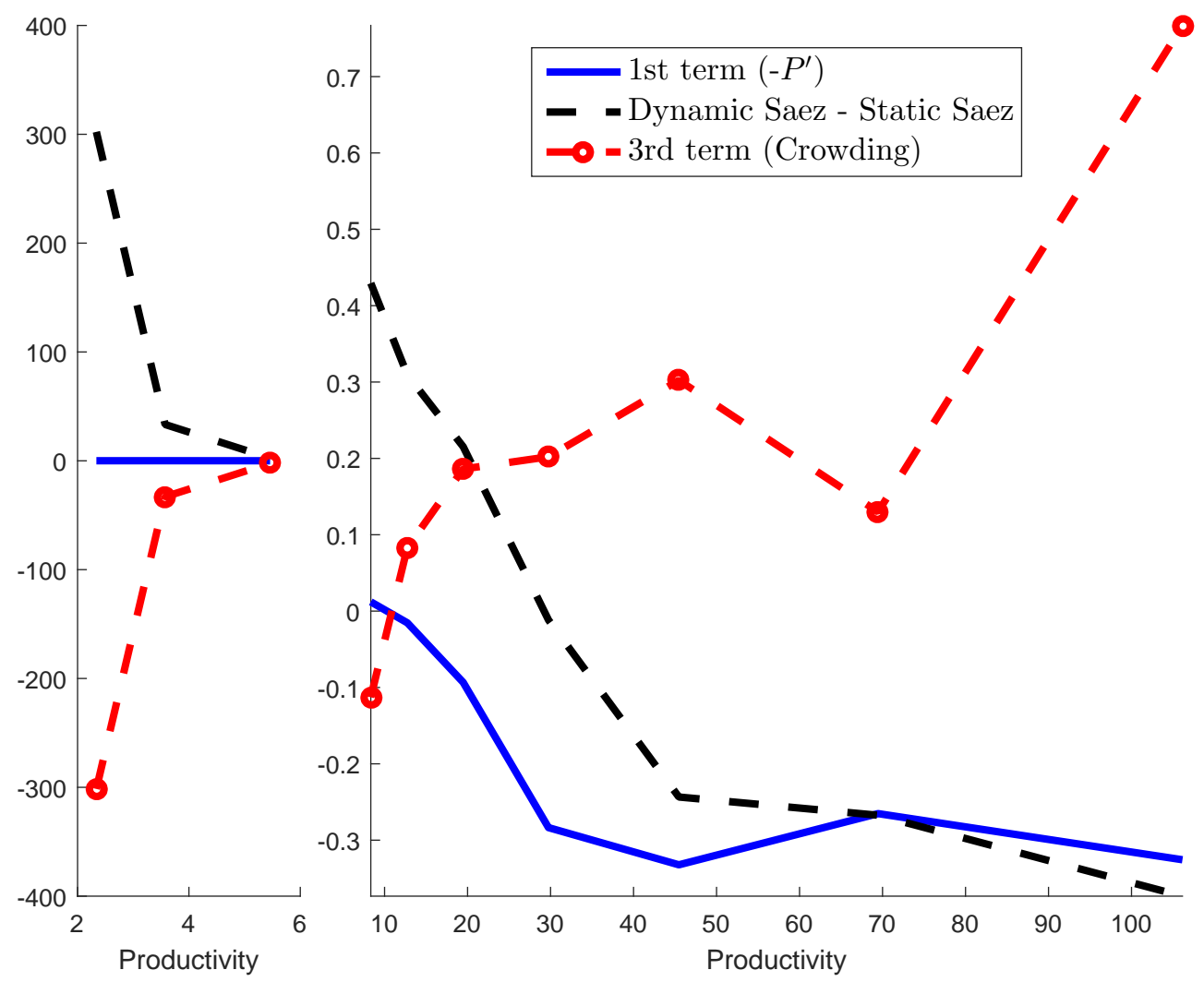

Note: The "1st term $\left(-P^{\prime}\right)$ " (solid line) represents the first term in our optimal tax formula (4). "Dynamic Saez - Static Saez" is the second term in our formula (4) minus the original Saez. The "3rd term (crowding)" represents the third term in our formula (4).

At the low income group (whose wages are less than \$8), marginal private savings are negative $\left(\tilde{P}^{\prime}<0\right)$, as shown in Figure 8. Low income households would like to borrow more at the margin. This has two impacts. First, the government increases the marginal tax rate to achieve the optimal total savings. The solid line (denoted by $-P^{\prime}$ ) in Figure 7 represents this substitution effect. Second, the negative marginal private savings rate amplifies the Saez effects - the dotted line denoted by "Dynamic Saez - Static Saez," which also pushes the optimal tax rate up. While the third component (dotted line with circles) shows negative values - the cross-sectional private 
Figure 8: Marginal Private Savings $P^{\prime}$

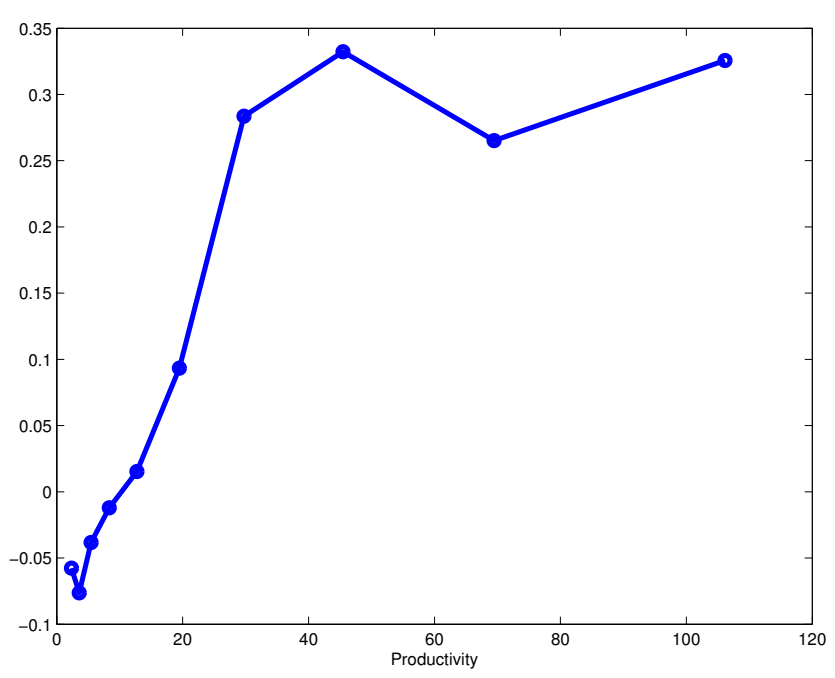

intermediation schedule becomes less progressive - the first and second components dominate this third component for this income group.

At the low-middle income group (whose wages are between $\$ 8$ and $\$ 25$ ) marginal private savings now become positive: workers would like to save with an additional income. This would lower the optimal marginal tax. However, the second component (dynamic Saez - static Saez) is still positive and big due to a large consumption inequality generated by an unequal wealth distribution. The third component now turns from a negative to a positive value - the private insurance schedule becomes more "progressive" — which calls for a higher tax rate. Overall, the second and third components dominate the first component, and thus, the optimal tax rate is higher in the presence of private insurance.

At the upper-middle and high income groups (whose wages are higher than $\$ 25$ ), marginal private savings are always positive, which calls for a lower optimal tax rate as private saving is a good substitute for public insurance. Moreover, the difference between the dynamic and static Saez terms is now negative - the Saez effects are mitigated: $\left(1-P^{\prime}\right)<1$. While the third term (the alignment of private progressivity) is positive - private insurance becomes more progressive the first and second components dominate the third component. At the very top income group (whose wage rates are higher than $\$ 100$ ), these effects offset each other, leaving the optimal tax rate similar to that without a private insurance market. ${ }^{16}$

\footnotetext{
${ }^{16}$ At the productivity level (between $\$ 50$ and $\$ 70$ ), the marginal savings rate slightly falls. This pattern is due
} 
In sum, the difference in tax rates with and without a private insurance market is quantitatively important, as the difference between the two can be as large as 10 percentage points. According to our benchmark model, for the low and lower-middle income group, the optimal tax rate is higher in the presence of a private market, mainly because of the amplified Saez effects. Higher consumption inequality driven by asset inequality makes the Saez effects stronger. Moreover, for the very low income group, households try to borrow at the margin $\left(1-P^{\prime}>1\right)$, which amplifies the Saez effects even more. For the middle to high income groups where marginal savings is positive, the substitution effect (the 1st term) and mitigating effect in Saez (the 2nd term) dominate the crowding in/out effects (the 3rd term), resulting in lower tax rates in the presence of a private market. At the very top income distribution, these forces almost cancel out each other, leaving the tax rate with private savings close to that without.

Figure 9 shows the marginal total intermediation across productivity levels, $E\left[M^{\prime}(z, a) \mid z\right]=$ $T^{\prime}(z)+E\left[P^{\prime}(z, a) \mid z\right]$. It clearly shows that the total marginal intermediation is larger in the presence of a private market. This is mainly driven by the high marginal propensity to save from the precautionary savings motive in our model economy. This also implies that in the presence of a private market, the government cannot perfectly reproduce the optimal insurance in an economy without a private market, because households (with an individual-specific history of productivity shocks) have different precautionary motives for saving. Since we do not allow a history-dependent tax, the government cannot design a tax schedule that is perfectly in line with private savings' incentives. This indicates that social welfare in the economy with a private market can be lower than that in the economy without a private market.

We now compare social welfare under three tax schedules: the optimal tax with a private market (based on our formula), the optimal tax without a private market (Saez (2001)) and the current U.S. tax (approximated by a log-linear form as in HSV). Social welfare is compared based on a constant-compensating differential in (steady-state) consumption. The welfare cost (or gain) of a tax system $T$ relative to our optimal tax formula $\left(T^{*}\right)$ is $\Delta$ that satisfies:

$$
\begin{aligned}
\int V(x, a ; \Delta) d \Phi(x, a ; T) & =S W F\left(T^{*}\right) \\
V(x, a ; \Delta) & =u((1+\Delta) c(x, a)-v(l(x, a)))+\beta E\left[V\left(x^{\prime}, a^{\prime}(x, a) ; \Delta\right) \mid x\right]
\end{aligned}
$$

to our modification of the transition probability to match the fat tail at the top. Recall that we generated a fatter tail by increasing the probability of drawing higher productivity at the two highest productivity grids. This leads to a decrease in marginal private savings because once you reach this level of productivity, it is more likely to stay at a high productivity level (less need for savings). In Section 5 below, this pattern disappears when we use a pure log-normal productivity process. 
Figure 9: Marginal Total Intermediation: (Tax + Savings)

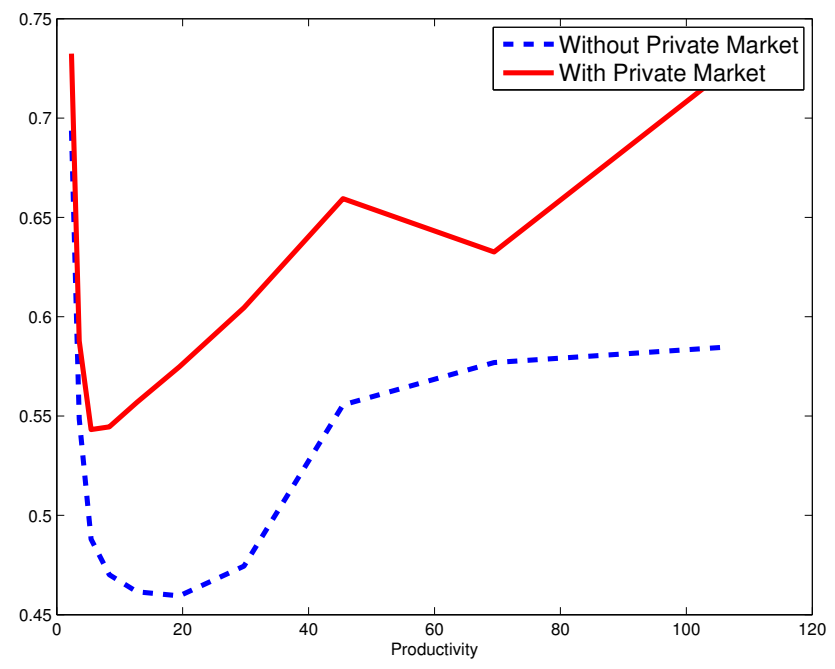

where $\Phi(a, x, T)$ is the steady-state distribution under tax system $T$ and $S W F\left(T^{*}\right)$ is the steadystate social welfare under our optimal tax (with a private market) schedule $T^{*}$. According to this measure, the welfare cost of U.S. tax system compared to our optimal tax schedule is $8.3 \%$. As we discussed above, it may generate higher welfare if the government simply shuts down the private insurance market and adopts the optimal tax without a private market (i.e., the original Saez (2001) formula). Indeed, social welfare under the optimal tax without a private market is higher than that with a private market by $9.2 \%$ (i.e., $\Delta=-9.2 \%$ ).

This result is not actually surprising, given that the market structure of private intermediation assumed in our quantitative analysis is rather primitive - the only asset available for households is a noncontingent bond for self-insurance. If the private market has richer tools for intermediation and faces less frictions than the government does, the welfare results can be quite different: social welfare under the optimal tax in the presence of a private market could be higher than that under the optimal tax without a private market. As Krueger and Perri (2006) point out, the incompletemarkets models tend to understate the consumption insurance compared to the data, implying that the market can do much better than the simple self-insurance assumed in many quantitative models. A richer structure of a private market should be investigated for a more reasonable welfare analysis, a topic we leave for future research.

Finally, we compare our optimal tax schedule to the current U.S. income tax rates. Figure 10 compares the optimal marginal tax rates implied by our model (solid line) to the current U.S. 

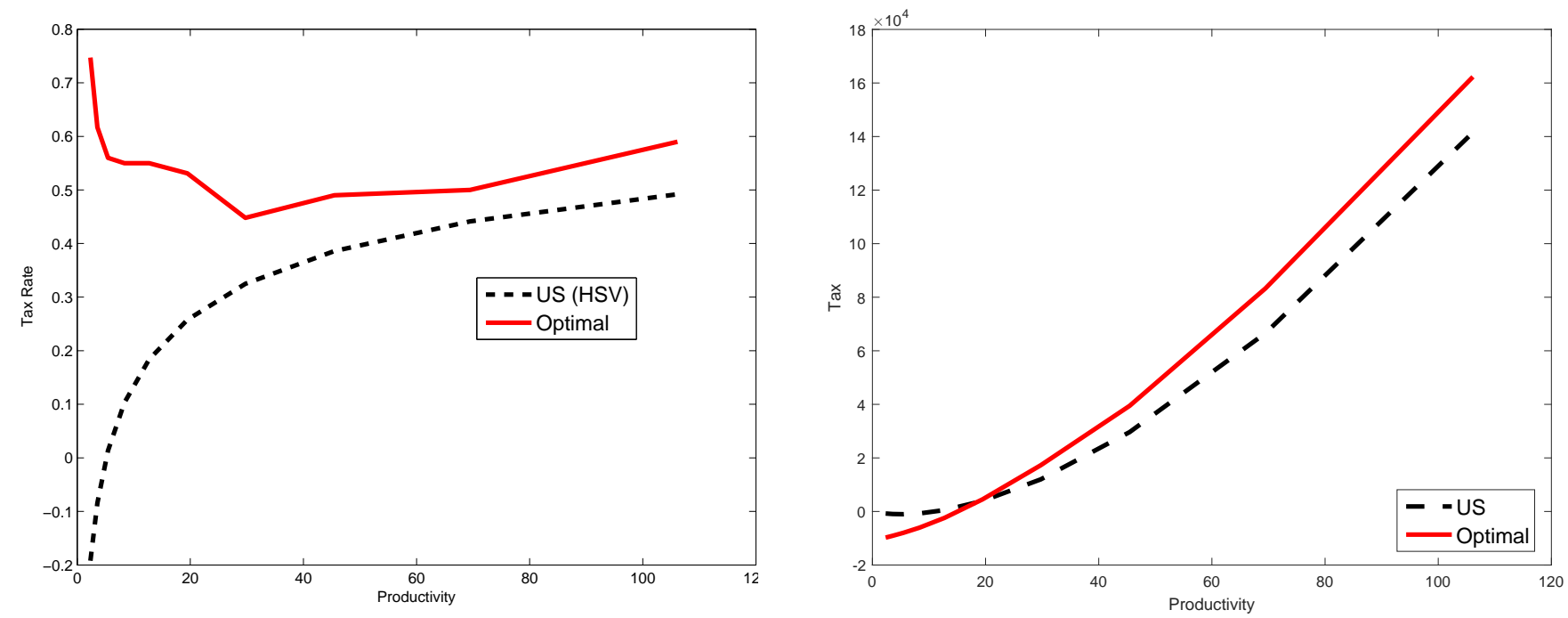

income tax schedule approximated by the HSV functional form (dotted line). First, the optimal marginal tax rates are much higher than the current rates in the U.S across all income levels, especially for the low income group as the optimal tax rates are U-shaped. ${ }^{17}$ Second, given that the amount of government purchase $\bar{E}$ - which is not valued by households - is assumed to be constant and identical between the two economies, the average amount of government transfers to poor households is larger under the optimal tax system. For example, the comparison of two net tax (total tax minus transfer) schedules, T(z)'s, in Figure 11 shows that households whose productivity is less than $\$ 18$ pay less tax (net of transfers) under the optimal tax system, despite higher marginal tax rates.

\section{Comparative Statistics}

Our formula shows that the optimal tax schedule depends on households' savings behavior as well as the standard sufficient statistics. In this section, we investigate how the optimal tax schedule varies with respect to different parameter values of relative risk aversion, the Frisch elasticity, the

\footnotetext{
${ }^{17}$ Heathcote and Tsujiyama (2017) find that the optimal tax schedule is close to a log-linear form. There are at least two important differences between Heathcote and Tsujiyama (2017)'s results and ours. First, we match the exact shape of the hazard rate of the productivity distribution in the data, while they approximate the productivity distribution by a exponentially-modified Gaussian. Second, they assume a complete separation between perfectly insurable and noninsurable productivity shocks, whereas we assume a partial insurance market.
} 
borrowing constraint, the persistence of productivity shocks, and the fat tails of income distribution. For each specification, we find a new value of $\beta$ to clear the private insurance market at $r=4 \%$, the steady-state interest rate under the current U.S. tax schedule (approximated by a log-linear form as in HSV). Simultaneously, we also look for a new value of the borrowing limit $\underline{a}$ so that about $10 \%$ of households are credit-constrained in the steady state - except for the comparative statics with respect to the borrowing limit itself.

\subsection{Risk Aversion and Labor Supply Elasticity}

We consider the relative risk aversion $\sigma=1$ (lower than the benchmark risk aversion: $\sigma=1.5$ ). Figure 12 shows the optimal tax rates without a private insurance market for $\sigma=1$ and 1.5 . With a smaller risk aversion, the optimal tax rates are lower than those in our benchmark at all productivity levels because there is less need for insurance. ${ }^{18}$ This driving force is still present in an economy with a private market.

In the presence of a private insurance market, however, the optimal tax rates at the upper-middle and high income groups are in fact higher when $\sigma=1$ (lower risk aversion) in Figure 13. This is because of the general equilibrium effect. With a smaller risk aversion, households save less (a weaker precautionary savings motive). The real interest rate has to increase to clear the private savings market. For example, the real interest rate net of discounting $\beta(1+r)$ increases from 0.9647 (under $\sigma=1.5$ ) to 0.9808 (under $\sigma=1$ ). This encourages high-income households to save more and makes the marginal private savings $\left(P^{\prime}\right)$ schedule steeper, which leads to a larger cross-sectional dispersion in assets and consumption. Thus, the second term and the third term in our formula (amplified Saez effects and aligned private progressivity effects) become larger. For upper-middle and high income groups (wages above \$30), this general equilibrium effect (larger second and third terms in the formula) dominates a weaker precautionary savings (smaller first term in the formula), resulting in higher marginal tax rates.

Next, we consider a smaller Frisch elasticity of labor supply $(e=0.25)$. Figure 14 shows that for all income levels the optimal tax rates under $e=0.25$ are higher than those in our benchmark $(e=0.5)$ because an inelastic labor supply is associated with a smaller cost of distortion.

\footnotetext{
${ }^{18}$ Under utilitarian social welfare, for example, the social welfare weights at high income levels $\left(\frac{u^{\prime}(c)}{A}\right)$ are relatively high when risk aversion is low.
} 
Figure 12: Optimal Tax without Private Insurance

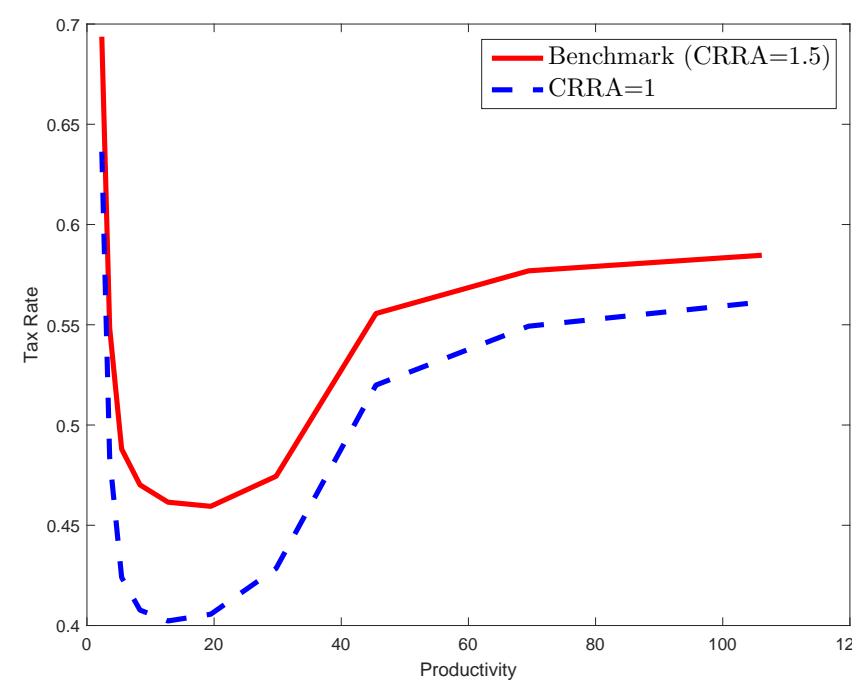

Figure 13: Optimal Tax with Private Insurance

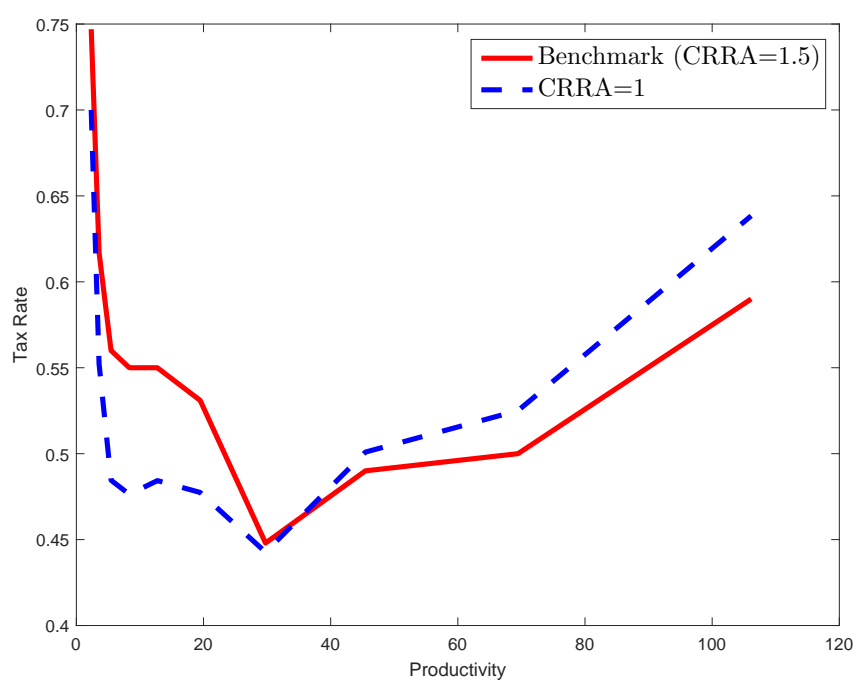

Figure 14: Optimal Tax with Private Market

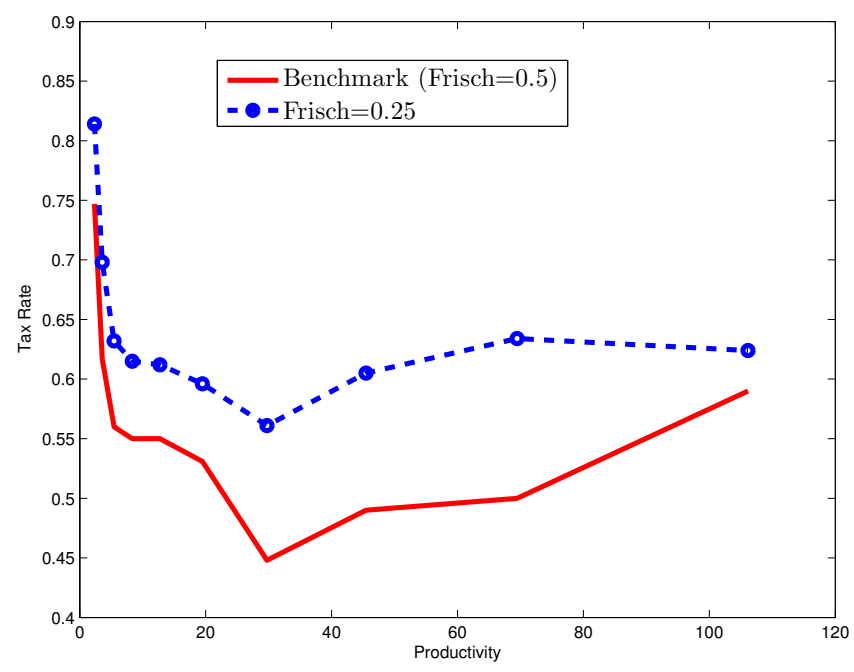

\subsection{Borrowing Constraints}

In the benchmark economy, we set the borrowing limit $\underline{a}=-86.55$ which is the average annual earnings in the steady state under the current U.S. tax schedule (approximated by a log-linear form as in HSV). Under this borrowing limit, 9.7\% of households are credit-constrained under the current U.S tax schedule. We consider a tighter borrowing limit, which is half of our benchmark case $(\underline{a}=-43.3)$ so that workers can borrow one-half of the average earnings in the economy. With 
Figure 15: Optimal Tax under Tighter Borrowing Constraint

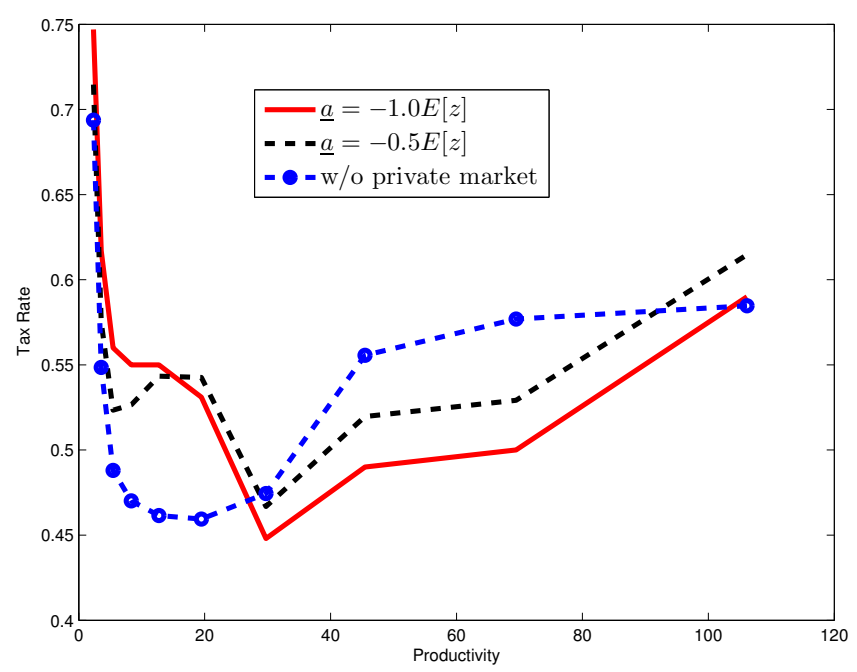

this tighter borrowing limit, about $34 \%$ of the population is credit-constrained under the current U.S. tax schedule in our model. Figure 15 shows the optimal tax rate schedules under this tighter borrowing constraint. The optimal tax rates are roughly between those in the benchmark and those without a private insurance market, except for the highest productivity group.

Under the tighter borrowing constraint, households tend to save more due to a stronger precautionary savings motive. To clear the private savings market, the equilibrium interest rate has to decrease. This increases the MPS of the low income group and decreases the MPS of the high income group. This will lead to a lower marginal tax for the low income group and a higher marginal tax for the high income group. In addition, the crowding in/out effects become larger under the tighter borrowing constraint as the tax reform induces a more progressive response of private savings. At the top income group, this effect is strong enough to generate an even higher optimal tax rate.

\subsection{Persistence of Productivity Shock}

Note that the persistence of the productivity shock, $\rho$, does not appear in the optimal tax formula (7) because we restrict our tax system to be noncontingent on history and the government maximizes steady-state welfare only in the benchmark analysis. However, the persistence of shocks affects households' savings pattern and, as a result, the optimal tax rate in the presence of a private insurance market. We examine the model with $\rho=0.8$ (lower persistence). We recalibrate the 

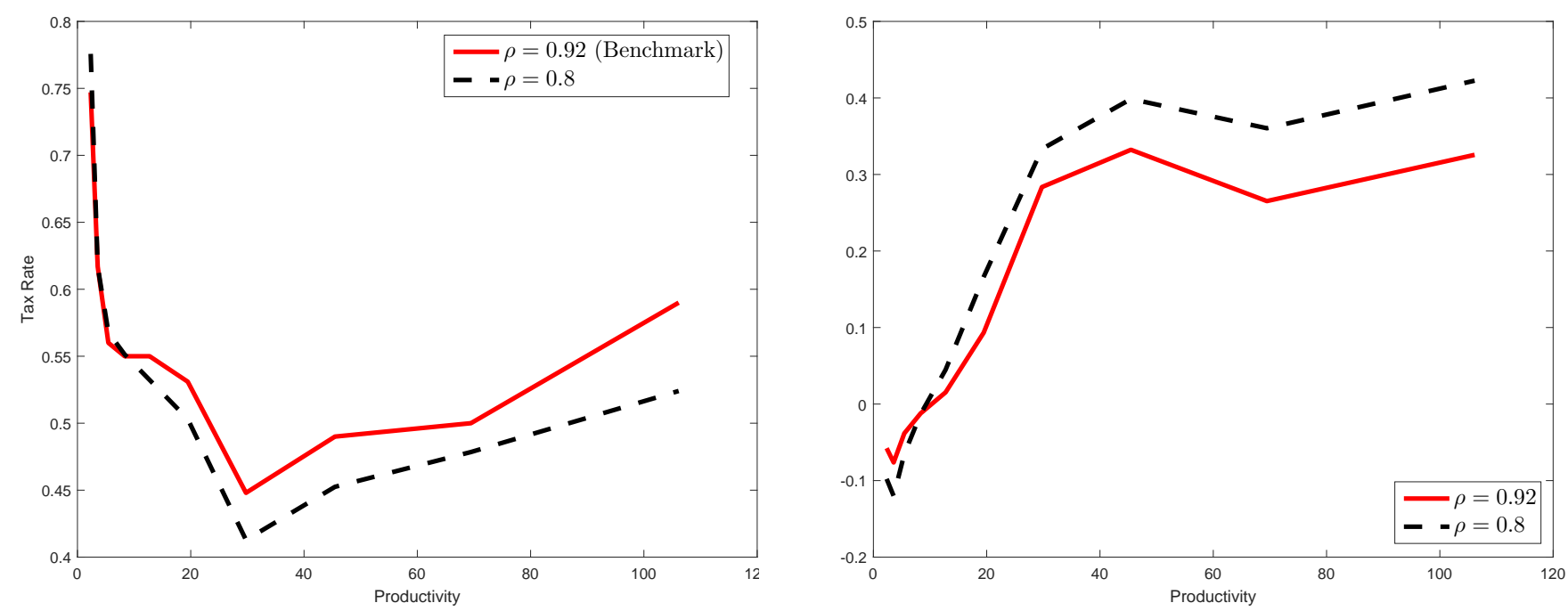

standard deviation to the innovation $\sigma_{\epsilon}$ to obtain the same standard deviation of log productivity, $\sigma_{x}=0.561$, in the benchmark. We also modify the transition probability matrix at both ends of the productivity distribution to match the hazard rates in the data, as we did in our benchmark case.

Figure 16 shows that the optimal tax rates under $\rho=0.8$ are smaller than those in the benchmark model except for the very low income (productivity) group. This is mainly driven by the marginal private savings $\left(P^{\prime}\right)$ shown in Figure 17. At the low income levels (wage rate below $\$ 5$ ), workers save less (borrow more) at the margin under $\rho=0.8$ because they expect that productivity will increase in the near future. This leads to higher tax rates via substitution effects and amplification of the Saez effects. For higher income levels (wage rate above $\$ 5$ ), the optimal tax rates under $\rho=0.8$ are higher because these workers save more at the margin, which leads to a lower marginal tax via substitution effects and mitigation of the Saez effects.

\subsection{Log-normal Distribution of Income: Effects of Fat Tails}

We have modified the transition probability (from the discretized log-normal distribution) to match the fat tail in the income (and wage) distribution in the data. To examine the role of the fat tail, we compute the optimal tax under a pure log-normal productivity process without modification. The hazard rate $\frac{x f(x)}{1-F(x)}$ of the log-normal distribution monotonically increases. This results in a monotonically decreasing tax rate without a private insurance market in Figure 18. The pattern 
Figure 18: Log-normal Distribution of Productivity

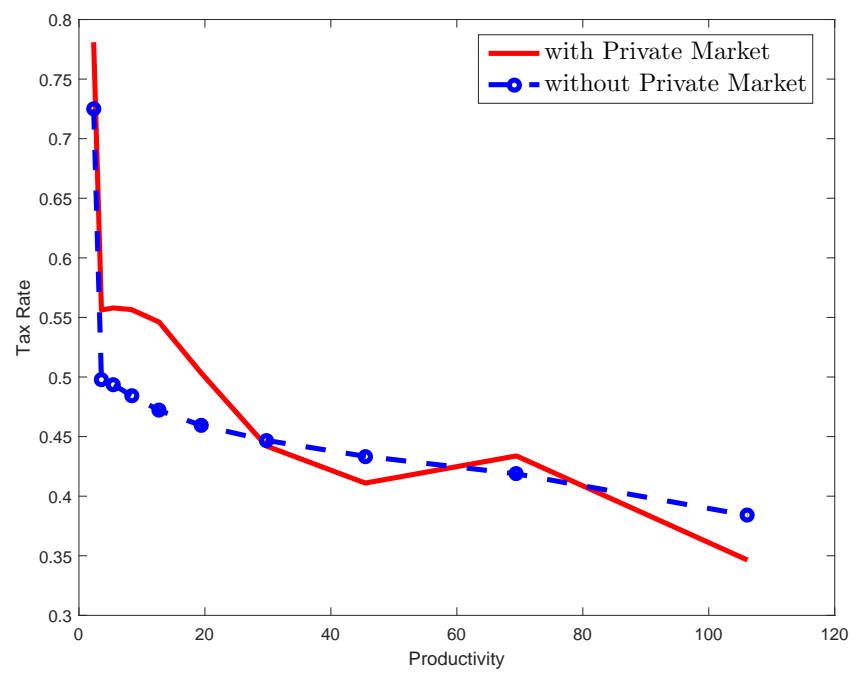

prevails in the presence of private insurance, suggesting that the fat tail is crucial for the U-shaped optimal marginal tax schedule.

\section{Conclusion}

We study a fully nonlinear optimal income tax schedule in the presence of a private market. As in Saez (2001), the optimal tax formula is expressed in terms of standard sufficient statistics such as the Frisch elasticity of labor supply, the hazard rate of the income distribution, and marginal social welfare weights. In the presence of a private market, however, these sufficient statistics are no longer sufficient. The optimal tax formula also depends on how private savings interact with public savings. First, the formula captures the fact that public insurance and private insurance are substitutes - a higher marginal private savings leads to a lower marginal tax rate at that income level. Second, the original welfare effects in Saez (2001) are either amplified or mitigated, depending on the marginal propensity to consume and cross-sectional consumption inequality. Third, a tax reform is more effective when the response of private insurance is aligned with the reform. For example, increasing the marginal tax rate is more desirable when private savings also become more progressive.

We compute the optimal tax schedule based on a general equilibrium model (Huggett (1993)) calibrated to resemble the U.S. income distribution. The presence of a private market is quanti- 
tatively important as the difference in optimal tax rates (with and without private insurance) can be as large as 10 percentage points. For the low and lower-middle income group, the optimal tax rate is higher in the presence of a private market, mainly because of the amplified Saez effects. For the middle to high income groups where marginal savings is positive, the substitution effect and the mitigating effect in the Saez formula dominate, resulting in lower tax rates in the presence of a private market. At the very top income distribution, these forces almost cancel out each other, leaving the tax rate similar to that of an economy without private insurance.

While our results provide transparent and intuitive insights about the role of a private market in the optimal income tax schedule, there are at least 4 limitations to our analysis. First, there is no wealth effect in the labor supply. Second, the transition dynamics are not considered in the welfare gains from tax reforms. Third, the market structure of private insurance is rather primitive (e.g., non-state contingent bonds only). Fourth, there is a restrictive tax system that depends on current labor income only. We leave a more thorough analysis that delves into these aspects for future work. 


\section{References}

Aiyagari, S., and E. R. McGrattan (1998): "The optimum quantity of debt," Journal of Monetary Economics, 42(3), 447-469.

Attanasio, O., and J. V. Ríos-Rull (2000): "Consumption smoothing in island economies: Can public insurance reduce welfare?," European Economic Review, 44(7), 1225-1258.

Bhandari, A., D. Evans, M. Golosov, and T. J. Sargent (2016): "Fiscal policy and debt management with incomplete markets," The Quarterly Journal of Economics, p. qjw041.

Chetty, R., and E. Saez (2010): "Optimal Taxation and Social Insurance with Endogenous Private Insurance," American Economic Journal: Economic Policy, 2(2), 85-116.

Conesa, J. C., S. Kitao, and D. Krueger (2009): "Taxing Capital? Not a Bad Idea after All!,” The American Economic Review, 99(1), 25-48.

Conesa, J. C., and D. Krueger (2006): "On the optimal progressivity of the income tax code," Journal of Monetary Economics, 53(7), 1425-1450.

Diamond, P. A. (1998): "Optimal Income Taxation: An Example with a U-Shaped Pattern of Optimal Marginal Tax Rates," The American Economic Review, 88(1), 83-95.

Farhi, E., and I. Werning (2013): "Insurance and Taxation over the Life Cycle," The Review of Economic Studies, 80(2), 596-635.

Floden, M., and J. Linde (2001): "Idiosyncratic Risk in the United States and Sweden: Is There a Role for Government Insurance?," Review of Economic Dynamics, 4(2), 406-437.

Golosov, M., M. Troshkin, and A. Tsyvinski (2016): "Redistribution and Social Insurance," American Economic Review, 106(2), 359-386.

Golosov, M., and A. Tsyvinski (2007): "Optimal Taxation with Endogenous Insurance Markets," The Quarterly Journal of Economics, 122(2), 487-534.

Golosov, M., A. Tsyvinski, and N. Werquin (2014): "A Variational Approach to the Analysis of Tax Systems," National Bureau of Economic Research Working Paper Series, No. 20780.

Greenwood, J., Z. Hercowitz, and G. W. Huffman (1988): "Investment, Capacity Utilization, and the Real Business Cycle," The American Economic Review, 78(3), 402-417. 
Heathcote, J., K. Storesletten, and G. L. Violante (2014): "Optimal Tax Progressivity: An Analytical Framework," National Bureau of Economic Research Working Paper Series, No. 19899.

Heathcote, J., and H. Tsujiyama (2017): "Optimal income taxation: Mirrlees meets Ramsey," Working Paper.

Huggett, M. (1993): "The risk-free rate in heterogeneous-agent incomplete-insurance economies," Journal of Economic Dynamics and Control, 17(5), 953-969.

Krueger, D., and F. Perri (2006): "Does Income Inequality Lead to Consumption Inequality? Evidence and Theory," The Review of Economic Studies, 73(1), 163-193.

— (2011): "Public versus private risk sharing," Journal of Economic Theory, 146(3), 920-956.

Mankiw, N. G., M. Weinzierl, and D. Yagan (2009): "Optimal Taxation in Theory and Practice," The Journal of Economic Perspectives, 23(4), 147-174.

Mirrlees, J. A. (1971): “An Exploration in the Theory of Optimum Income Taxation," The Review of Economic Studies, 38(2), 175-208.

Narajabad, B. N. (2012): "Information technology and the rise of household bankruptcy," Review of Economic Dynamics, 15(4), 526-550.

Ramsey, F. P. (1927): “A Contribution to the Theory of Taxation," The Economic Journal, 37(145), $47-61$.

Saez, E. (2001): "Using Elasticities to Derive Optimal Income Tax Rates," The Review of Economic Studies, 68(1), 205-229.

Saez, E., and S. Stantcheva (2016): "A Simpler Theory of Optimal Capital Taxation," National Bureau of Economic Research Working Paper Series, No. 22664.

Tauchen, G. (1986): "Finite state Markov-chain approximations to univariate and vector autoregressions," Economics Letters, 20(2), 177-181. 